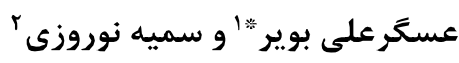

اكروه مهرندسى كامييوتر، دانشكده فناورى اطلاعات، دانشكاه شهيد مدنى آذربايجان، تبريز، ايران

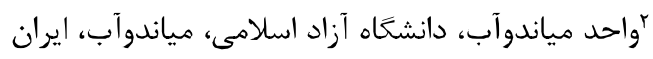

با توجه به رشد سريع شبكههاى اجتماعى در جند سال اخير، مسأله نمونه تهيرى از ترافهاى بسيار بزرى شبكههاى اجتماعى با هدف

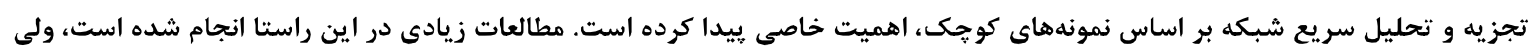

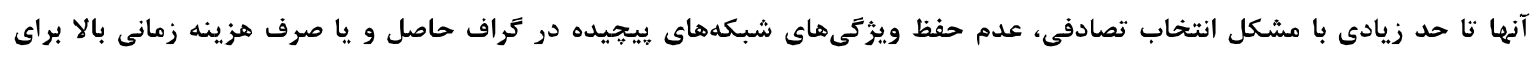

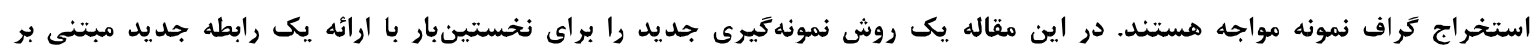

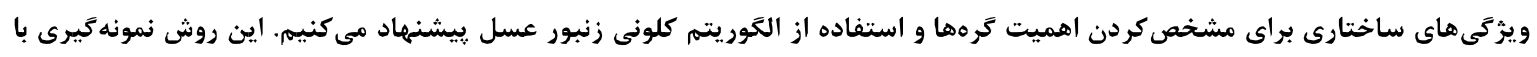

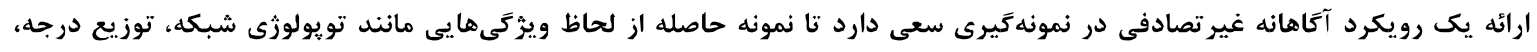

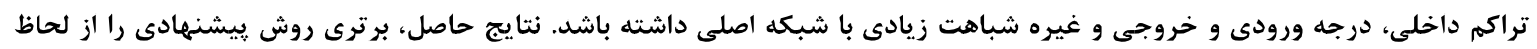

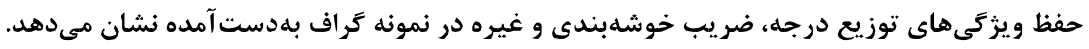

وازَّان كليدى: نمونه كيرى، شبكههاى اجتماعى، ضريب خوشهبندى، كلونى زنبور عسل

\title{
Sampling from social networks's graph based on topological properties and bee colony algorithm
}

\author{
Asgarali Bouyer ${ }^{* 1}$ \& Somayeh Norouzi ${ }^{2}$ \\ ${ }^{1}$ Department of Computer Engineering, Azarbaijan Shahid Madani University, Tabriz, Iran \\ ${ }^{2}$ Department of Computer, Miyandoab branch, Islamic Azad University, Miyandoab, Iran
}

\begin{abstract}
In recent years, the sampling problem in massive graphs of social networks has attracted much attention for fast analyzing a small and good sample instead of a huge network. Many algorithms have been proposed for sampling of social network' graph. The purpose of these algorithms is to create a sample that is approximately similar to the original network's graph in terms of properties such as degree distribution, clustering coefficient, internal density and community structures, etc. There are various sampling methods such as random walk-based methods, methods based on the shortest path, graph partitioning-based algorithms, and etc. Each group of methods has its own pros and cones. The main drawback of these methods is the lack of attention to the high time complexity in making the sample graph and the quality of the obtained sample graph. In this paper, we propose a new sampling method by proposing a new equation based on the structural properties of social networks and combining it with bee colony algorithm. This sampling method uses an informed and non-random approach so that the generated samples are similar to the original network in terms of features such as network topological properties, degree distribution, internal density, and preserving the clustering coefficient and community structures. Due to the random nature of initial population generation in meta-heuristic sampling methods such as genetic algorithms and other evolutionary algorithms, in our proposed method, the idea of consciously selecting nodes in producing


the initial solutions is presented. In this method, based on the finding hub and semi-hub nodes as well as other important nodes such as core nodes, it is tried to maintain the presence of these important nodes in producing the initial solutions and the obtained samples as much as possible. This leads to obtain a highquality final sample which is close to the quality of the main network. In this method, the obtained sample graph is well compatible with the main network and can preserve the main characteristics of the original network such as topology, the number of communities, and the large component of the original graph as much as possible in sample network. Non-random and conscious selection of nodes and their involvement in the initial steps of sample extraction have two important advantages in the proposed method. The first advantage is the stability of the new method in extracting high quality samples in each time. In other words, despite the random behavior of the bee algorithm, the obtained samples in the final phase mostly have close quality to each other. Another advantage of the proposed method is the satisfactory running time of the proposed algorithm in finding a new sample. In fact, perhaps the first question for asking is about time complexity and relatively slow convergence of the bee colony algorithm. In response, due to the conscious selection of important nodes and using them in the initial solutions, it generates high quality solutions for the bee colony algorithm in terms of fitness function calculation. The experimental results on real world networks show that the proposed method is the best to preserve the degree distribution parameters, clustering coefficient, and community structure in comparison to other method.

Keywords: Sampling, Social networks, Clustering coefficient, Artificial Bee Colony

$$
\begin{aligned}
& \text { ضريب خوشهبندى' و غيره در نمونه شبكه بادستآمده، } \\
& \text { مورد ارزيابى قرار مى حيرد. بررسى اين خواص از نمونه شبكه }
\end{aligned}
$$

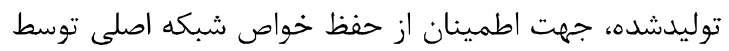

$$
\begin{aligned}
& \text { آن الكوريتم نمونه كيرى است [9-7]. از روشهاى محبوب و و } \\
& \text { سريع براى نمونه }
\end{aligned}
$$

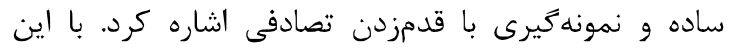

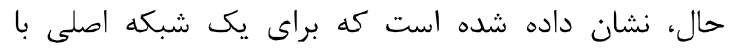

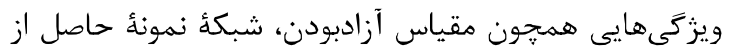

$$
\begin{aligned}
& \text { روشهاى تصادفى در بيشتر مواقع، از ويززيى هاى شبكههاى }
\end{aligned}
$$

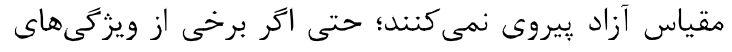

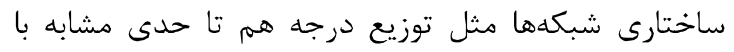

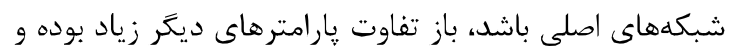

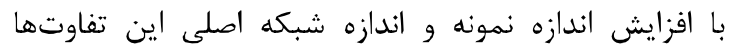

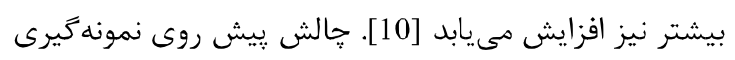

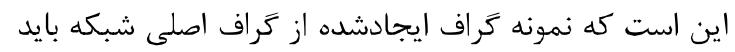

$$
\begin{aligned}
& \text { مناسب و قابل اعتماد باشد؛ بهطورىكه بتواند خواص اصلى }
\end{aligned}
$$

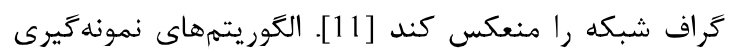

$$
\begin{aligned}
& \text { مى توانند هم قطعى و هم احتمالى باشند كه بر روى } \\
& \text { مجموعه كوجكىى از خارامترها وابسته هستند و ارزيابى اعتبار }
\end{aligned}
$$

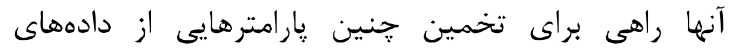

$$
\begin{aligned}
& \text { مشاهده شده است [12]. تعيين اهميت كرهها بر اساس لهاس }
\end{aligned}
$$

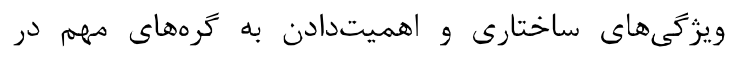

$$
\begin{aligned}
& \text { فرايند نمونهبردارى و نيز سعى در بلدستآوردن نمونهمايى }
\end{aligned}
$$

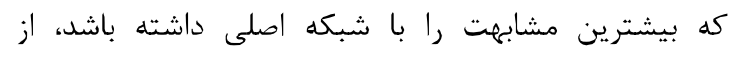

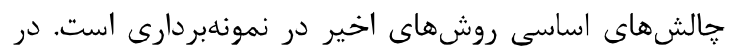

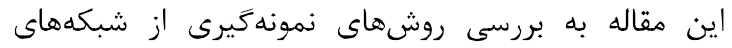

${ }^{2}$ Clustering Coefficient

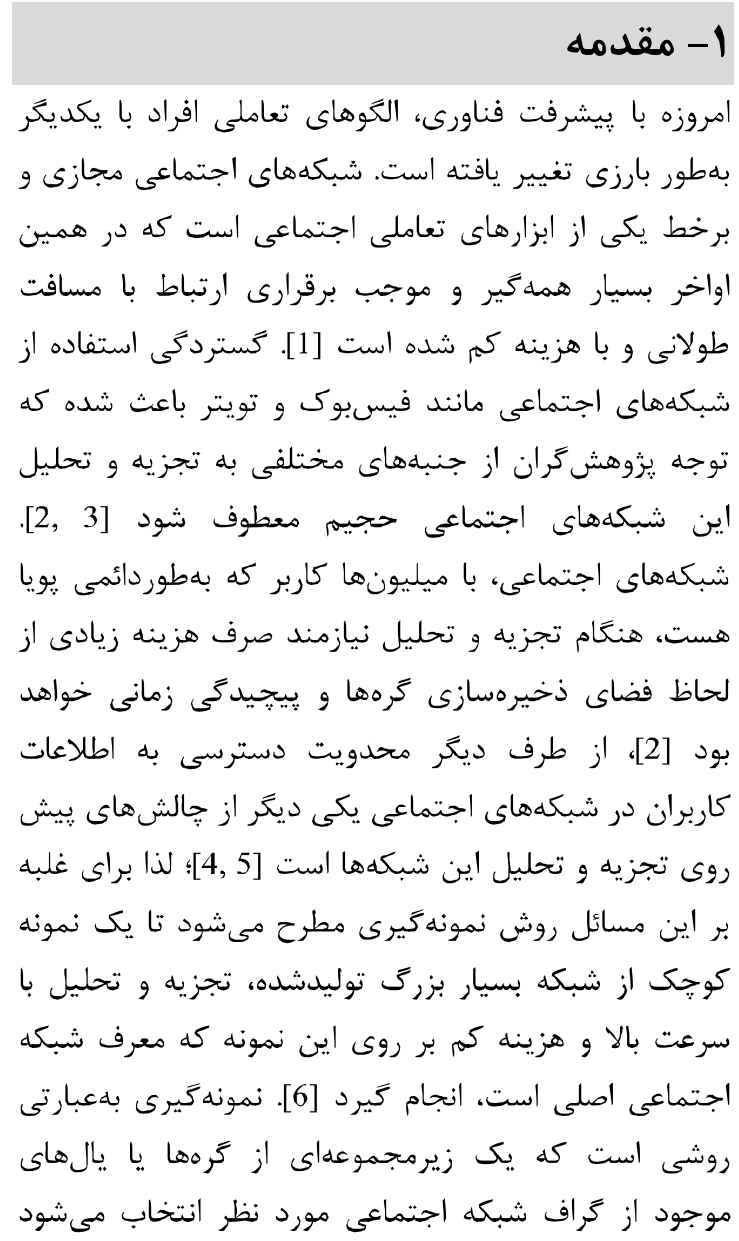

الكَوريتمهاى زيادى براى نمونهكيرى از شبكههاى

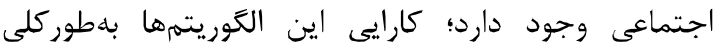

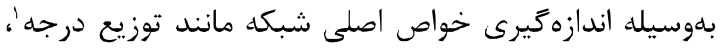

${ }^{1}$ Distribution Degree 


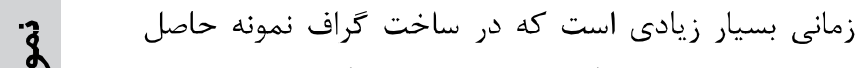

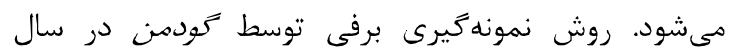

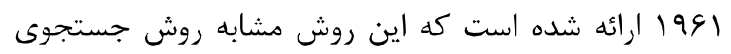

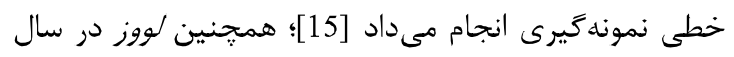

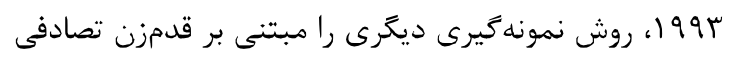

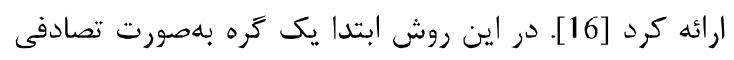

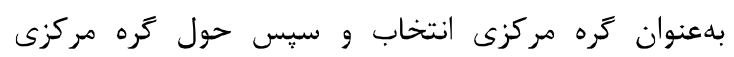

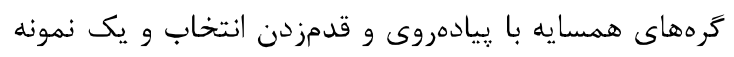

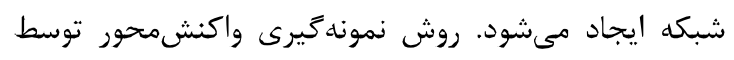

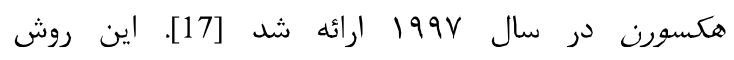

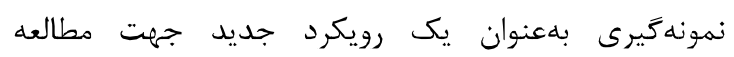

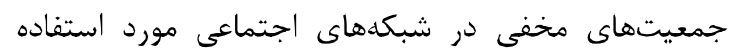

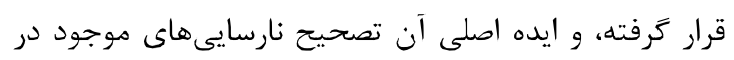

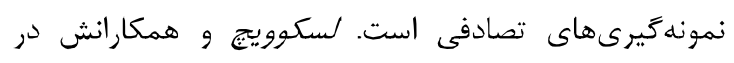

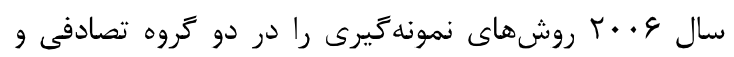

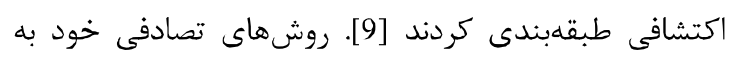

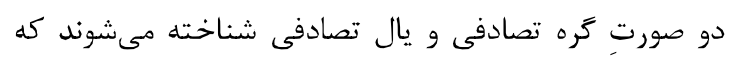

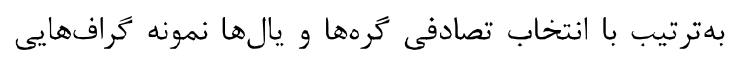

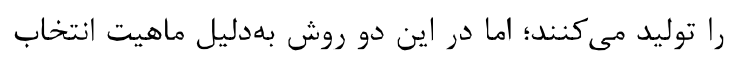

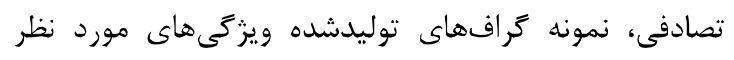

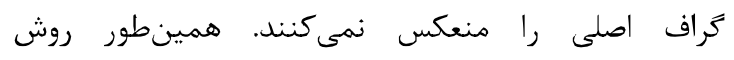

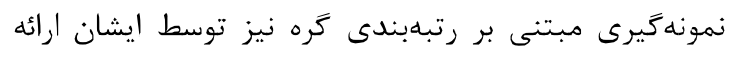

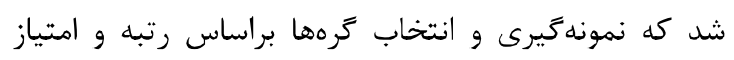

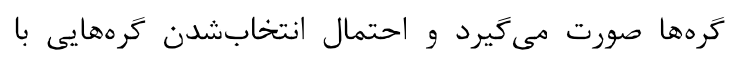

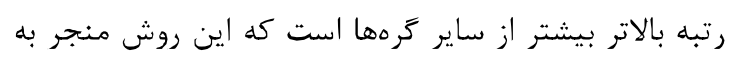

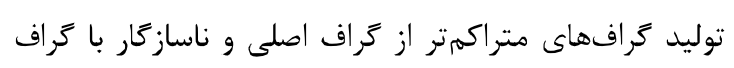

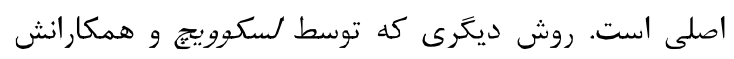

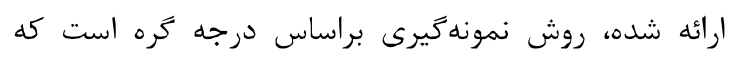

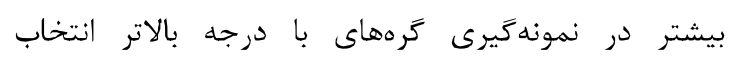

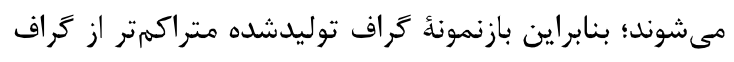

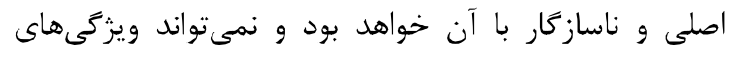

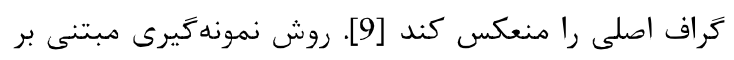

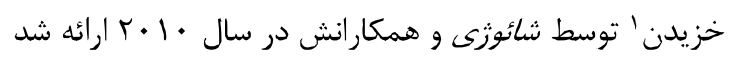

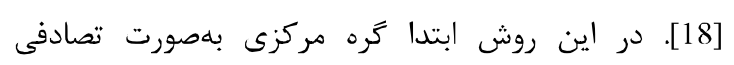

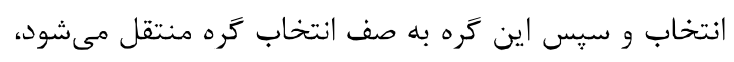

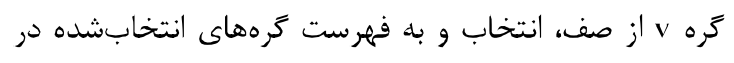

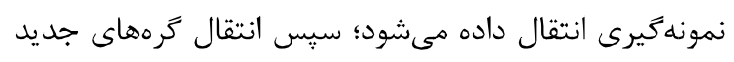

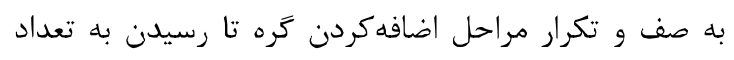

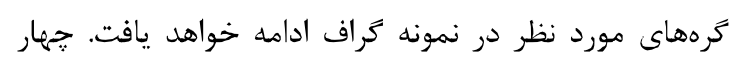

${ }^{1}$ Crawling
اجتماعى بِيجيده برداخته و روش جديدى را براى رفع

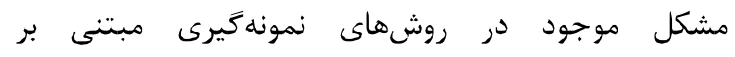

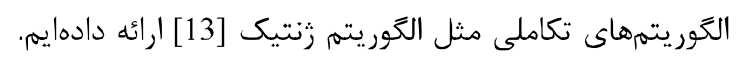

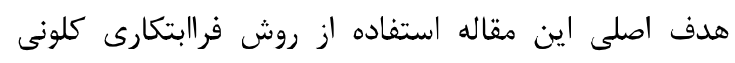

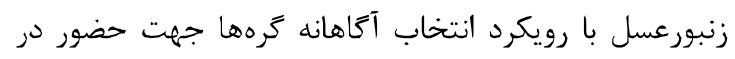

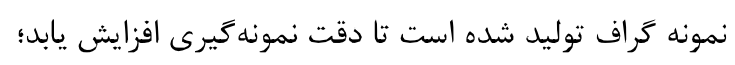

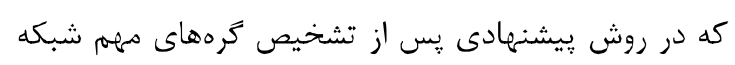

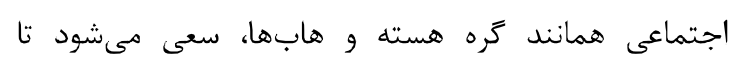

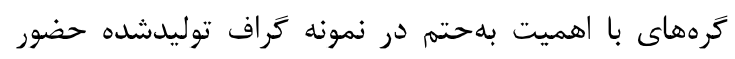

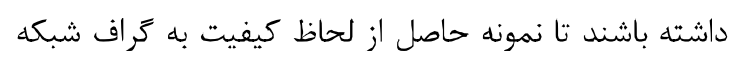

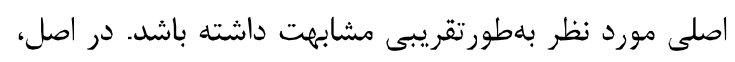

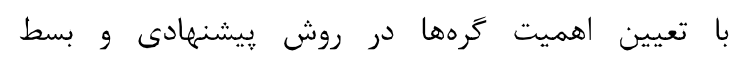

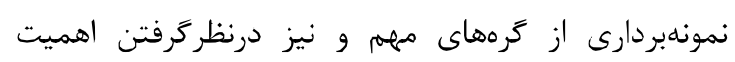

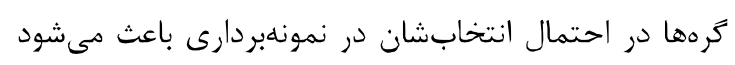

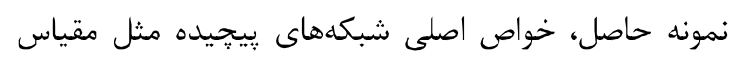

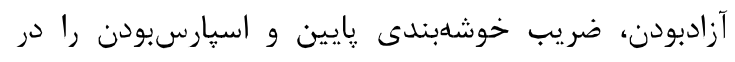

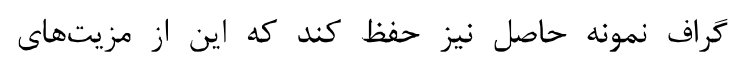
اساسى روش يُشنهادى محسوب مئشود.

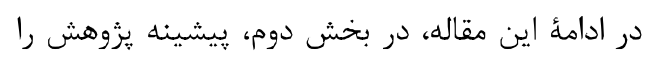

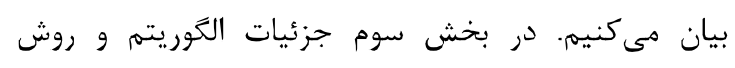

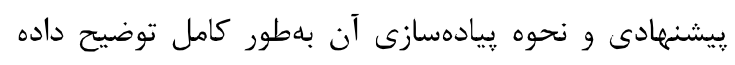

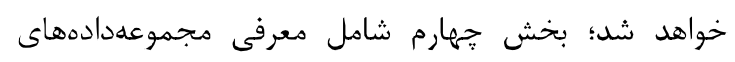

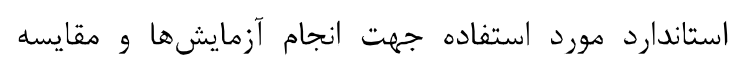

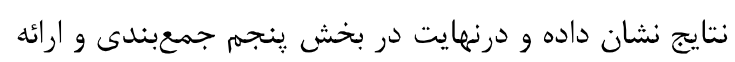
نتايج كلى و بيشنهادهايى براى كارهاى آينده بيان مىشودي

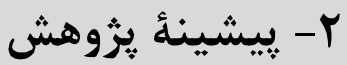

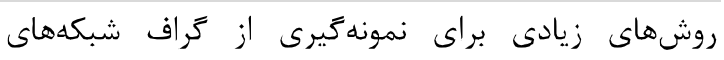

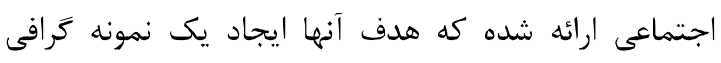

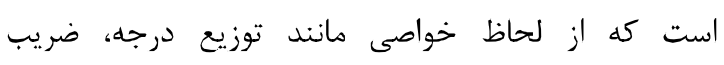

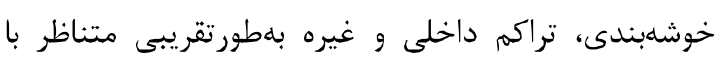

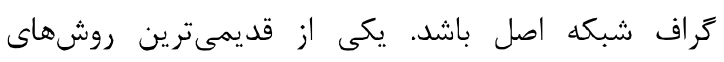

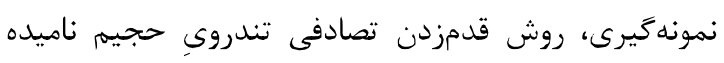

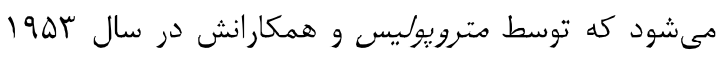

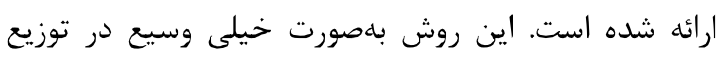

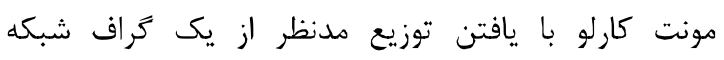

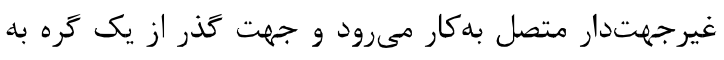

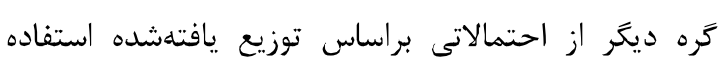

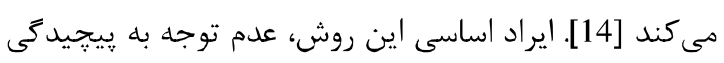


به انجمنهايى، براى هر كره يك ضريب اجتماع دحاسبه و

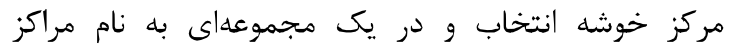

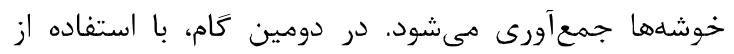

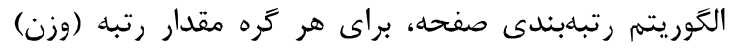

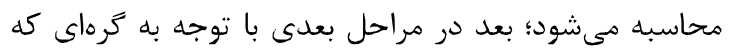

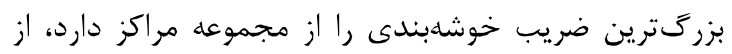

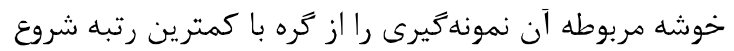

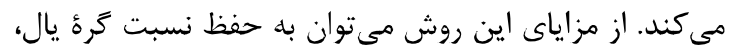
حفظ تقريبى ساختار انجمنى و ارتباطات اشاره كرد [21].

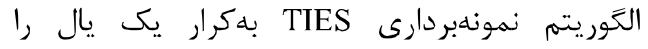
بلصورت تصادفى از كراف شبكأ اجتماعى انتخاب كرده و

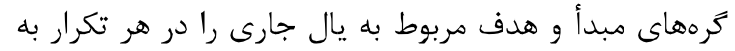

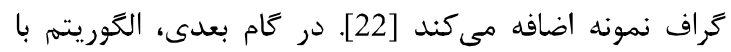

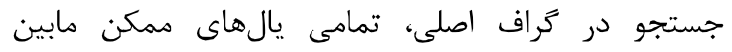
كرههاى انتخابشده از تراف اصلى را به كراف نمونه اضافه

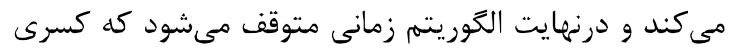

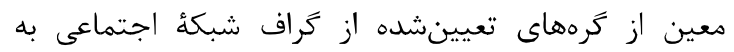

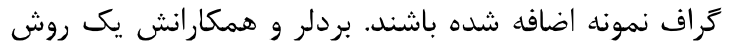

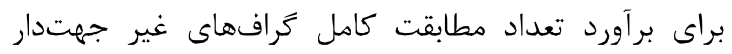

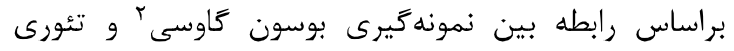

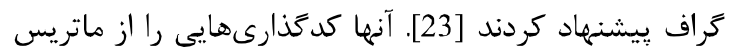

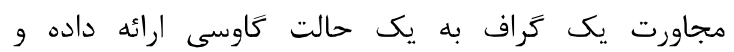

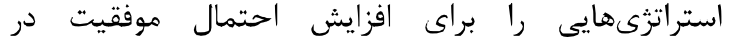

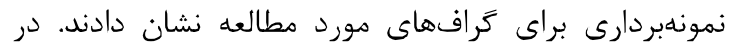
يك كار ديكرى، روش نمونهبردارى بر اساس كرافهائ هران هدف

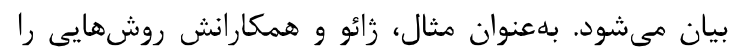

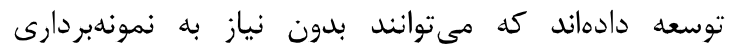
يكنواخت رئوس، يك تراف را بهطور مؤثر نمونهبردارى كنيند

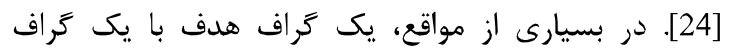

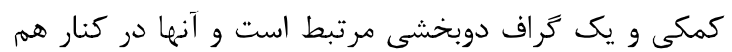

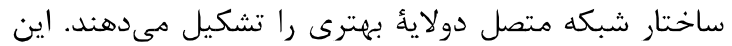

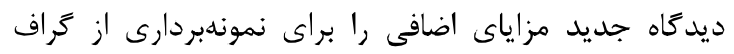

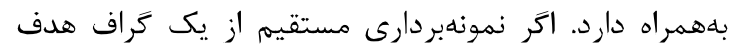

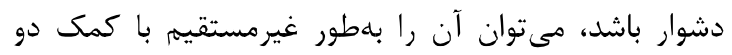

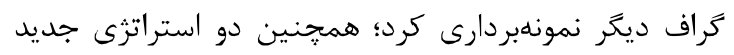

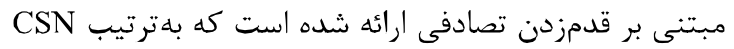

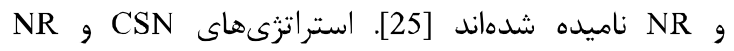

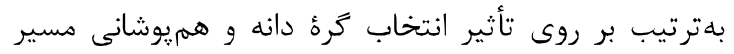

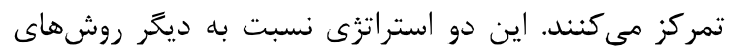

${ }^{2}$ Gaussian boson
الكوريتمى كه براى انتخاب كره و خزش آن مورد استفاده

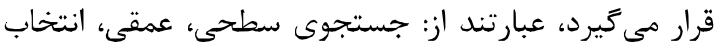

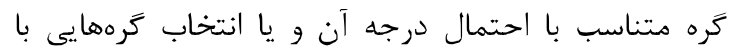

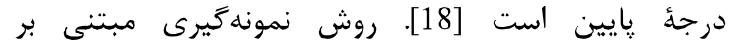

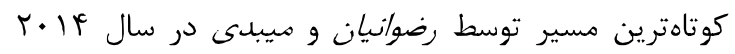

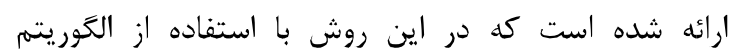

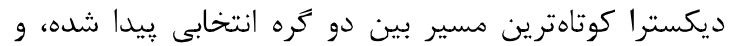

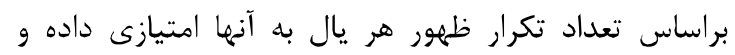
نمونه با انتخاب يك درصد معينى از ترهها با رتبه بالا ايجاد مىشود [19]. روش نمونه كيرى مبتنى بر الكوريتم زنتيك از از

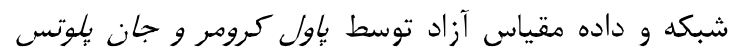
ارائه شده است، تا از كراف شبكههاى اجتماعى به داده روش

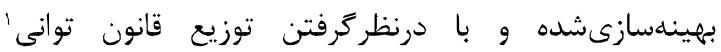
نمونه كيرى انجام كيرد [13]. از نتايج بهدستآمده از ائن ائن روش كارايى بالاى آن نسبت به الكوريتمهاى تصادفى از

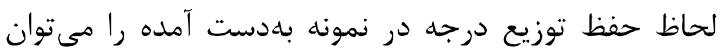

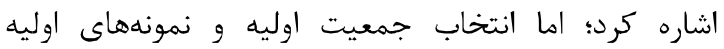
بلهصورت تصادفى از معايب اين روش است. اين روش كارايى

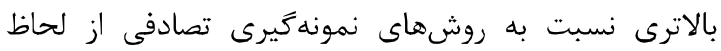

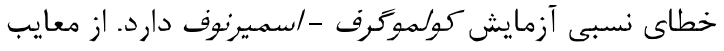

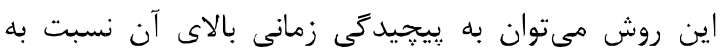

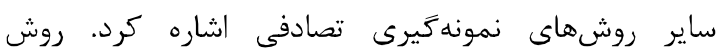

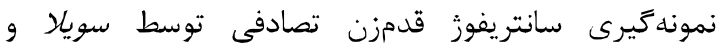

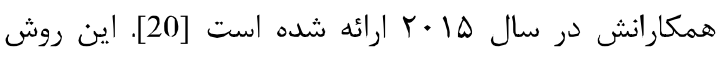

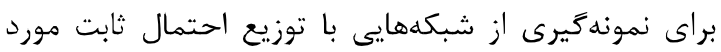

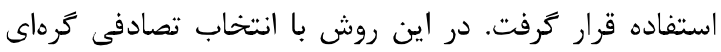

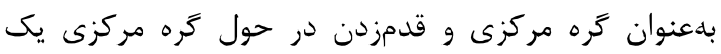
درخت يوشا ايجاد كرده كه در اين درخت يوشا وزن هر كرّه

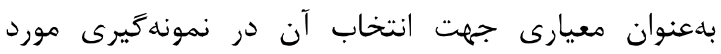

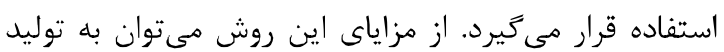

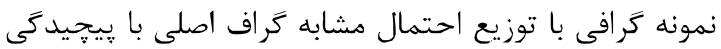

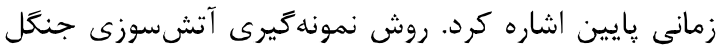
بر اساس رتبهبندى صفحه توسط تانَّ و همكار انش در سال

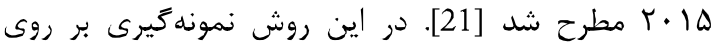

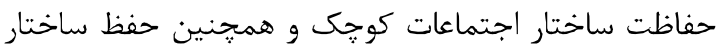
شبكه اصلى متمركز ميىشود؛ جون ساختار انجمن، توزيع

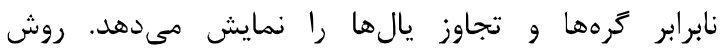

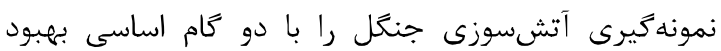
بخشيده است كه در نخستين كام بعد از يارتيشنبندى كرى كراف

${ }^{1}$ Power Law 
ورودى: گرافهاى مربوط به شبكههاى اجتماعى

خروجى: نمونه كراف كوجى توليدشده از روى گراف اصلى | - تنظيمات اوليه را انجام بده:

a

$$
\text { و تعيين اندازه شبكه اصلى؛ }
$$

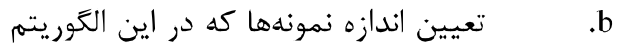

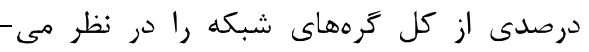

$$
\text { كيريم؛ }
$$

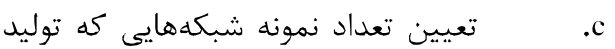

مىشود؛

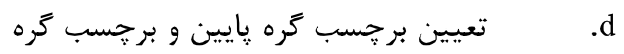

$$
\text { بالا و تعداد تكرار الكَوريته. }
$$

Y- تعداد NB زنبور (نمونه) ايجاد كن كه در ابتدا هر

زنبور عسل يك آرايه k عضوى است (هر كدام از

اين نمونهها داراى k تا گره خواهند بود).

r- - تعداد NF زنبور را بهدنبال منابع غذايى ارسال كن

(بهطورمعمول NF را نصف NB در نظر مى ميريم).

F- مقدار حلقه را براى L كام تنظيم كن (بهطورمعمول

( $\mathrm{L}=100$

هـ مقدار ضريب تنبيه كه زنبور عسل بهاندازه

محدودى اطراف يك منبع غذايى حضور داشته

باشد و درصورت عدم يافتن منبع غذايى بعد از تعداد تكرار معينى بهتر است، آن هحل را ترك كند

$$
\text { و در محل ديغرى حضور يابد. }
$$

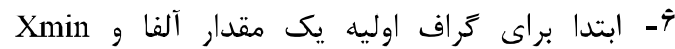

$$
\text { براساس درجه گرهها محاسبه كن. }
$$

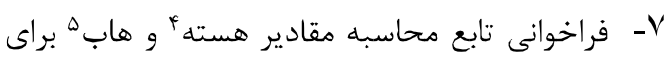

تمامى كرهها جهت انتخاب آكاهانه گرهها در فرايند

Corenode $(\mathrm{i})=\frac{\mathrm{Di}+\sum_{j=1}^{m} d i j}{M}$

$$
\text { نمونه ميرى. }
$$

人- فرمول (1) تا حد بسيار زيادى بلدست آوردن ارزش

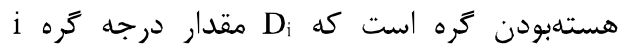

بوده، ون

$$
\text { نيز تعداد همسايههاى كره i است }
$$

Hubnode $(\mathrm{i})=\mathrm{D}_{\mathrm{i}} * \frac{1}{C C i+0.01}+\frac{\sum_{i}^{m} d j i}{m}$

\section{${ }^{3}$ Trial}

${ }^{4}$ Core

${ }^{5} \mathrm{Hub}$
مبتنى بر قدمزدن تصادفى، كارايى بهنسبه بهترى در برخى

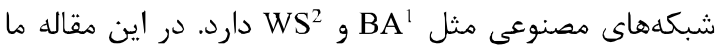
روش خود را با هر دوى اينما مقايسه كردهايم.

\section{r- ب - روش ييشنههادى}

در اين مقاله براى نخستينبار الكوريته كلونى زنبورعسل بههمراه يكى رابطه جديد ميتنى بر ويزگى هاى ساختارى

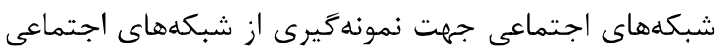
קيادهسازى شده است. با توجه به ماهيت تصادفىبودن انتخاب جمعيت اوليه در روشهاى نمونهَيرى فرابتكارى مثل الخوريتهم زنتيك و ديكر الگوريتمهاى تكاملى، ما در روش ييشنهادى اين مقاله، ايده انتخاب آكاهانه كرهها جهت

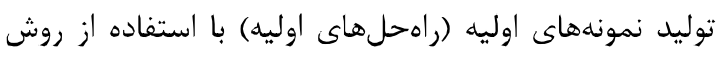

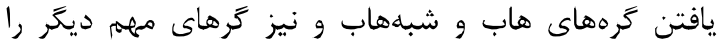
مثل هستهها بهمنظور تلاش براى حضور گرههاى مهلم در

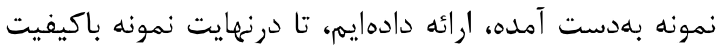
بالا و نزديك به كيفيت شبكه اصلى از لحاظ ويزگى ها

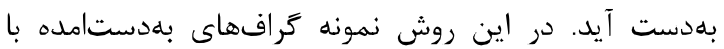
شبكه اصلى سازكارى خوبى داشته و مىتواند خصوصيات شبكه اصلى از جمله تويولوزى و حتى تعداد اجتماعات و ونى همبندبودن مؤلفه عظيم گراف نمونه اصلى را تا حد ممكن

\begin{tabular}{|c|c|}
\hline كلونى زنبورعسل & نمونه كيرى \\
\hline Bec & نمونه كراف \\
\hline NB & تعداد كل نمونهها \\
\hline NF & تعداد نمونههاى اوليه \\
\hline Lower bound & 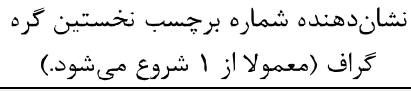 \\
\hline Upper bound & نشاندهنده شماره برجسب آخرين \\
\hline Iteration & تعداد كذرها \\
\hline Trial & محدوديت \\
\hline Cost-Fit & ميزان كيفيت \\
\hline
\end{tabular}
حفظ مى كند. در جدول (1) اصطلاحات معادل الكوريتهم كلونى زنبور عسل با نمونه كيرى از شبكههاى اجتماعى، داء

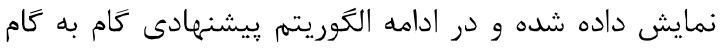

$$
\text { تفسير شده است. }
$$

(جدول-1): اصطلاحات كلونى زنبور عسل در نمونهَيرى

(Table-1): Terms of bee colony in sampling

مراحل الكَوريتم يِيشنهادى مبتنى بر كلونى زنبور عسل بهصورت كَام به كَام در زير بيان مىشود:

\footnotetext{
${ }^{1}$ Barabási-Albert

${ }^{2}$ Watts-Strogtz
} 


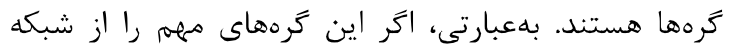

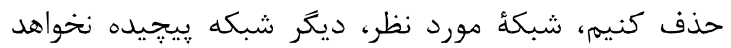

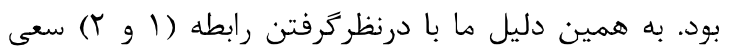

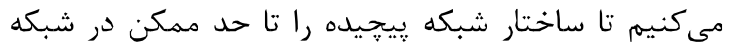
نمونهبردارىشده جديد حفظ كنيم. اين كار بهصورت مستقيم باعث حفظ ويزگى مقياس آزادبودن شبكه ميىشود و

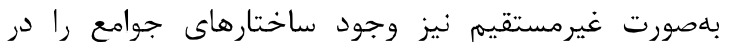

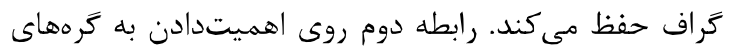

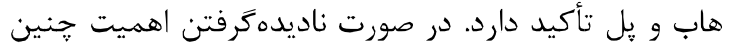
كرّهايى، كراف نمونه حاصل، به مؤلفههاى مختلفى شكسته مىشود و بنابر اين نمونه حاصل، نماينده خوبى براى شبكه

$$
\text { اصلى نخواهد بود. }
$$

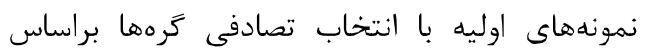

جرخ رولتى كه برمبناى مقادير بهدستآمده از فرمولهاى

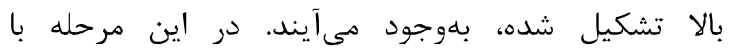

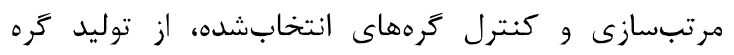
تكرارى در هر نمونه جلوگيرى مكى مرد. مقادير متغيرهاى و X براى شبكه اصلى بعد از بهدستآوردن درجه

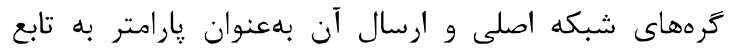
توزيع قانون توانى كه ييادهازى شده است، بهدست مى آيد. مقادير

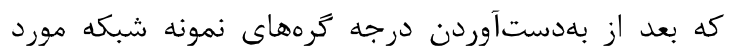

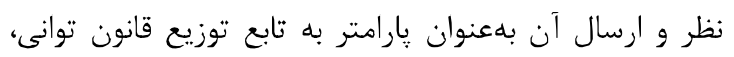
بلدست مىآيند. مقدار كيفيت هر نمونه توسط تارئ تابع

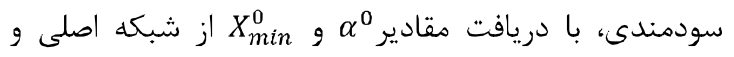
مقادير ماد $\alpha^{c}$

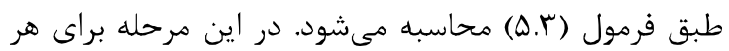
نمونه شبكه يك مقدار كيفيت محاسبه مى شودو.

$$
\operatorname{Fit}(\mathrm{c})=\frac{1}{2}\left(\sqrt{\left(\alpha^{0}-\alpha^{c}\right)^{2}}+\sqrt{\left(\mathrm{X}_{\min }^{0}-\mathrm{X}_{\min }^{\mathrm{c}}\right)^{2}}\right)
$$

تا اين مرحله نمونهشبكههاى اوليهاى توليد شدهاند، كه شامل يك مقدار كيفيتى نيز هستند. در اين مرحله ابتدا

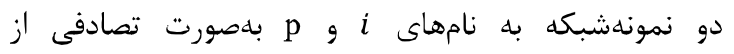

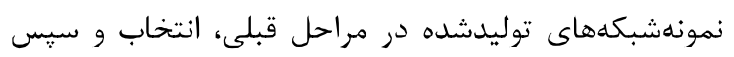

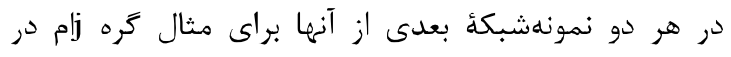

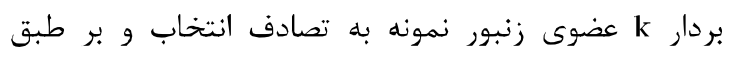
فرمول زير يك برجسب جديد براى آن نمونه محاسبه

مىشود (حركت به سمت گره جديد و توليد نمونه جديد).

Newfood.par $(j)=\left(\right.$ newfood.par $(j)+$ unifrnd $(-1,1)^{*}$ (newfood.par(j)-food(p).par(j)))
9- در فرمول (r) مقار، مقدر) نشاندهنده ميزان شباهت گره به گرoهاى hub در شبكه است، 的 $d_{i}$

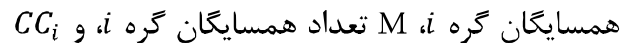
ضريب خوشهبندى هر كره است. با توجه به اينكه ضريب خوشلبندى مىتواند صفر باشد، بنابراين جهت جلوَيرى از صفربودن مخرج يك عدد ثابت

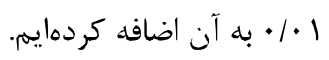

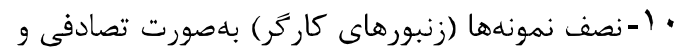
همانند روش يايه الكوريتم كلونى زنبور عسل توليد

$$
\text { مىشوند. }
$$

ا'ا-نصف ديخر نمونهما بهطوركامل آكاهانه توليد

مىشوند. گرoهايى در اين نمونهها حضور خواهند يافت كه مقدار هسته يا هاببودن بيشترى داشئ داشته

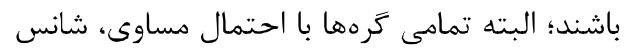

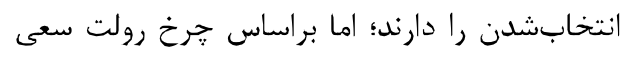
كرديم زرههايى كه مقدار هاب يا هسته بيشترى دارند، شانش بيشترى نيز در انتخابشدن داشته باشند، و گرههاى با مقدار كمتر نيز احتمال انتخاب

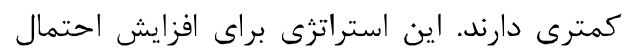
انتخاب گرمهاى مهلم و حضور آنها در نمونه شبكه

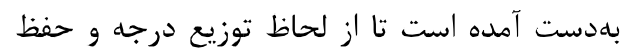

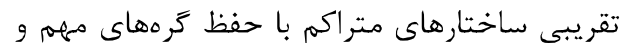
اساسى، شباهت زيادى به شبكه اصلى داشته باشد.

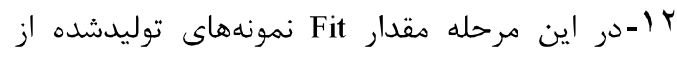
طريق تابع سودمندى ' محاسبه مىشود. هدف از

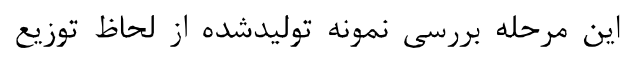
قانون توانى بوده تا نمونهاى كه كمترين مقدار را داشته باشد، بهعنوان نمونهاى كه به شباهت

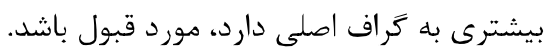
rا--در هر مرحله كمترين مقدار Fit مربوط بيه نمونه،

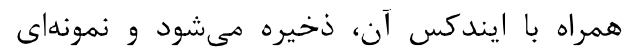
بهترين نمونه خواهد بود كد از نظر مقدار آلفا و وحيره

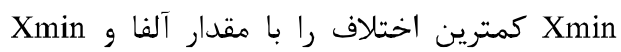
كراف اصلى داشته باشد. يكى از تفاوتهاى بارز شبكههاى ييجيده، داشتن

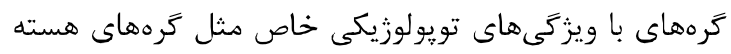

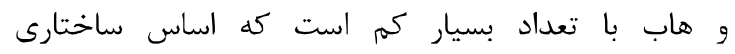
شبكهاى ييجيدهاى مثل شبكههاى اجتماعى وابسته به اين

${ }^{1}$ Fitness Function 
يكى ديكر از مزاياى روش ييشنهادى، سرعت خوب

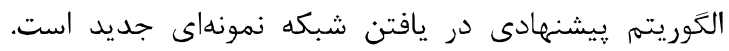

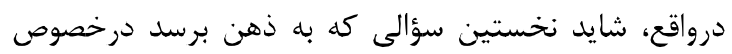

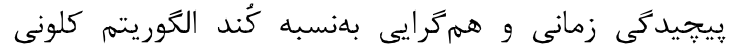

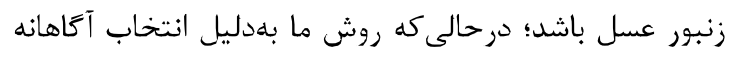

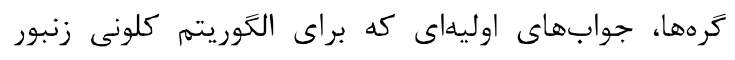
عسل توليد مىكند، كيفيت بالايى از نظر محاسبه تابع إنائ

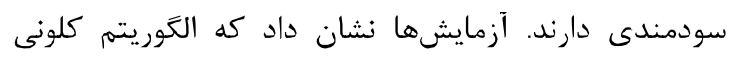

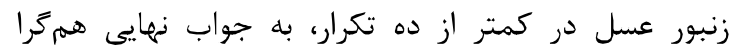

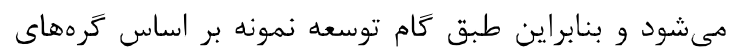

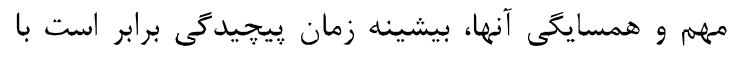

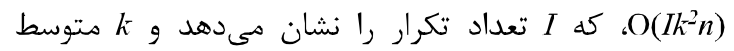

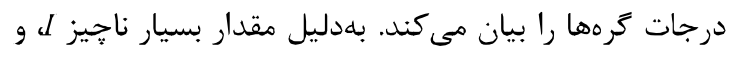

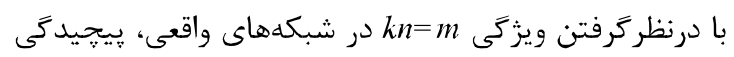

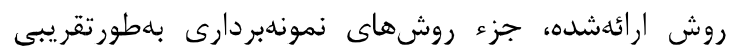

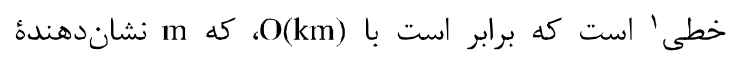

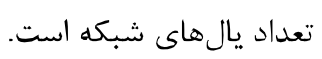

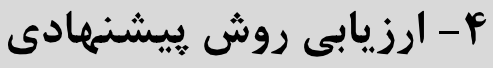

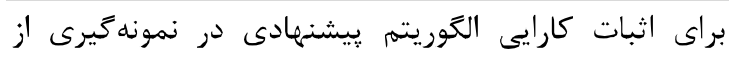

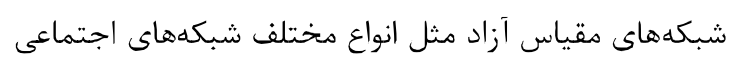

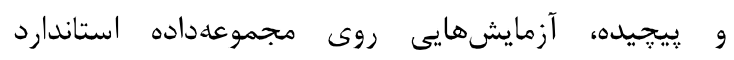

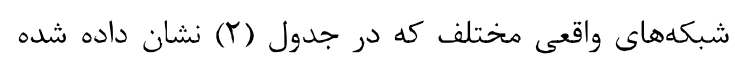

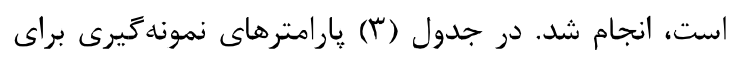

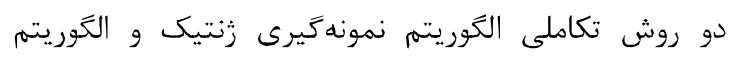

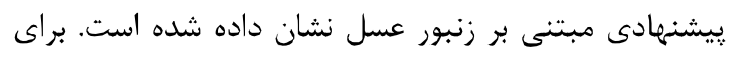

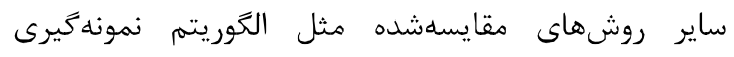

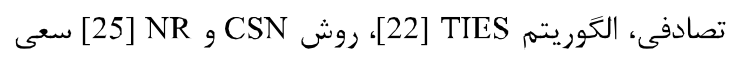

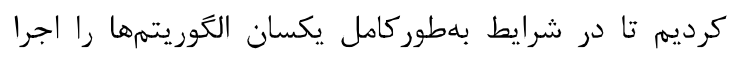

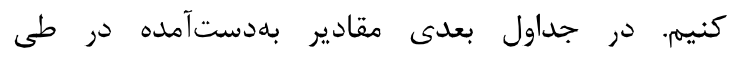

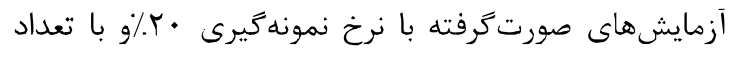

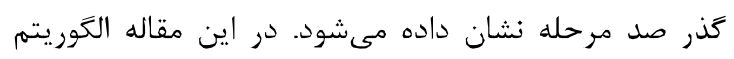

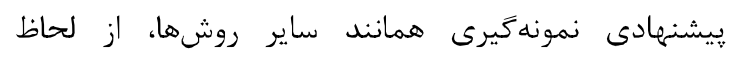

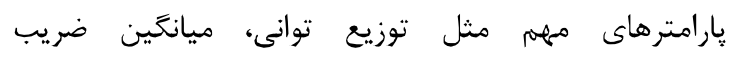

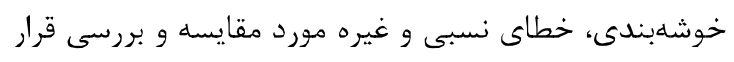
مى خيرد.

براى بررسى كارآيى روش خيشنهادى، دقايسة بين

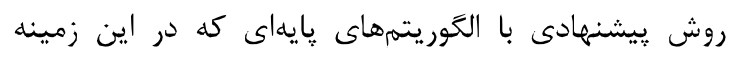

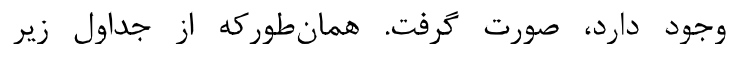

${ }^{1}$ Near linear
بعد از توليد نمونهشبكه جديد، مقدار كيفيت نمونهشبكه جديد محاسبه مىشود؛ اگر كيفيت نمونهشبكه

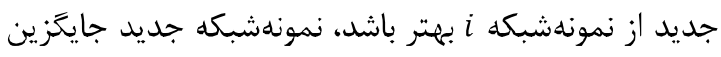

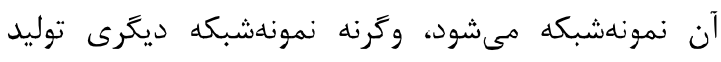

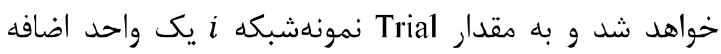
مىشود؛ و اين روند تا رسيدن به تعداد مورد نظرى از نمونه-

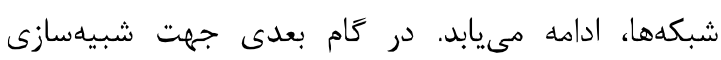
حركت زنبورهاى ناظر با توليد نمونهشبكههاى جدائ جديد براساس ميزان كيفيت نمونهشبكههاى قبلى صورت مى زئيرد. ابتدا هرخ رولتى براساس ميزان كيفيت نمونهشبكههاى

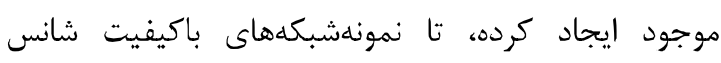

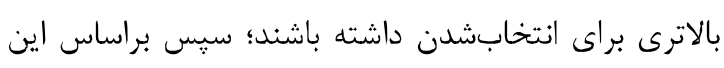

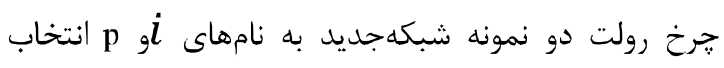

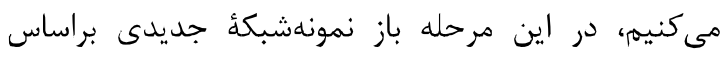

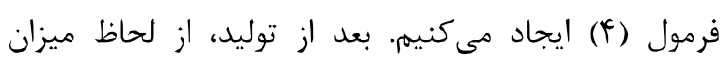

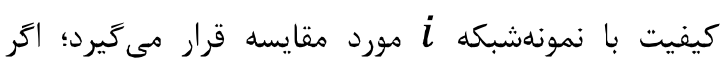

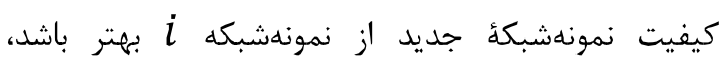

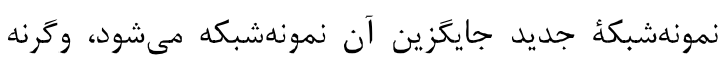

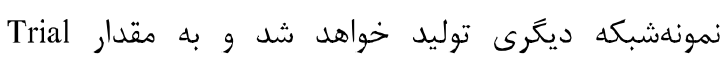

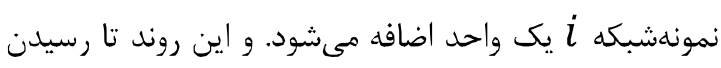

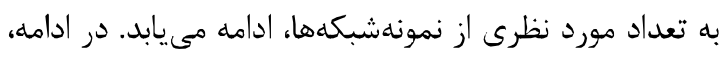

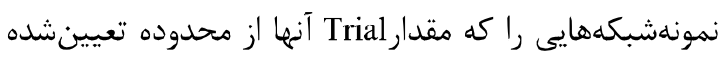

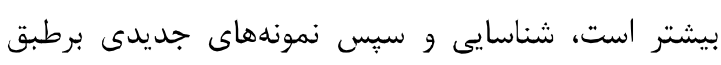

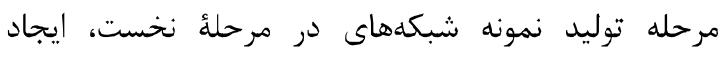

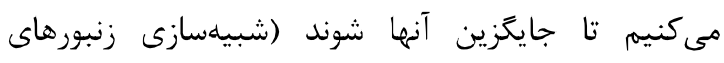

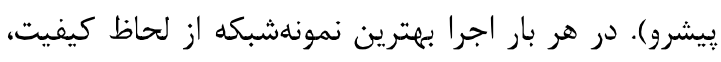

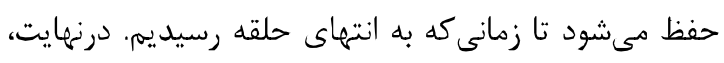

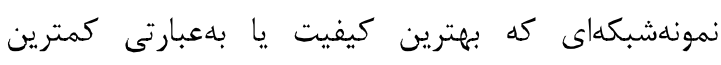
اختلاف را از نظر توزيع درجه با شبكه اصلى داشته باشد، باته توليد مىشود. يك مزيت مهم روش بيشنهادى، يايدارى روش جديد

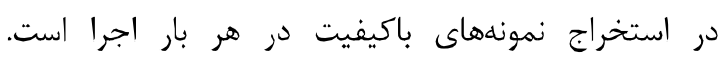

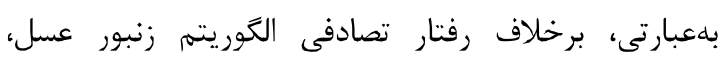

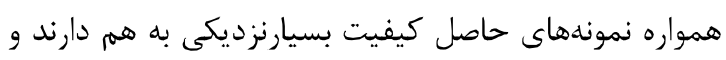

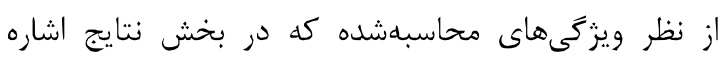

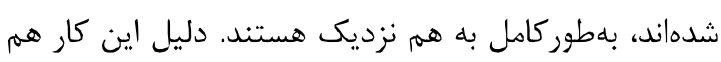

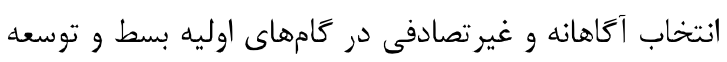
نمونها است. 
شبكه اصلى در همه شبكههاى واقعى بهجز مجموعهدادگان Dolphins اين مقايسه، روش CSN قرار دارد. بدترين نتايج بهدستآمده

$$
\text { نيز مربوط به روش نمونهبردارى تصادفى است. }
$$

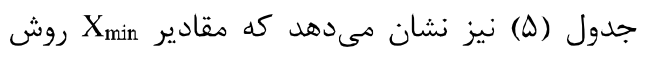

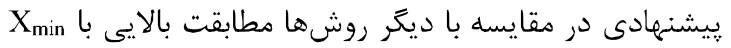

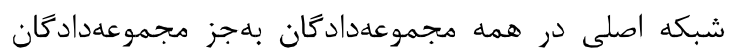
NR Internet_Routers-22july6 در رتبه دوم و نمونهبردارى تصادفى در آخرين رتبه قرار

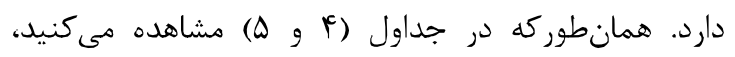

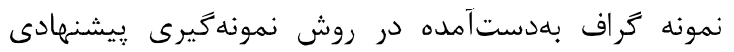
ثابت مى كند كه از لحاظ ويزگى تويولوزيكى توزيع درجه قانون توانى به كراف اصلى خيلى شبيه بوده و اختلاف اندكى باهم دارند كه اين نشاندهنده حفظ توزيع درجه قانون توانى در نمونه گراف بهدستآمده است؛ درحالى كه در در نمونه كرافهاى بلهدستآمده از طريق روشهونه بهدسي ديخر مثل روش نمونهگيرى تصادفى يا روش نمونهبردارى با الكوريتم زنتيك

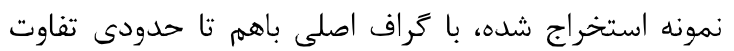
داشته و اين نشاندهنده عدم حفظ توزيع درجه در نمونه كراف بهدستآمده است.

\section{r-F- آناليز براساس آزمايش كولموكروف}

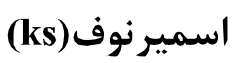

آناليز براساس آزمايش كولموكروف اسميرنوف(ks) درواقع

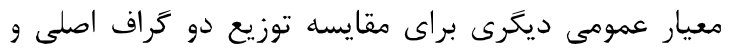

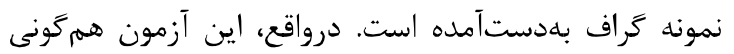
بين فراوانىهاى تجمعى را در دو توزيع گراف اصلى و زراف نمونلبردارىشده بررسى مى كند. نتايج بهدست آمده در در بازه

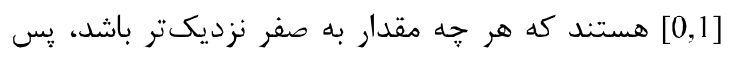

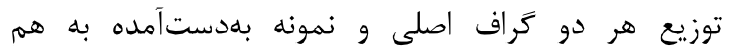

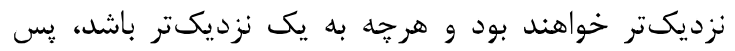

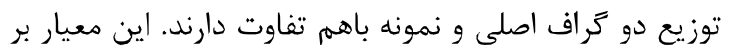

$$
\text { اساس رابطة رياضى زير تعريف مى شودي: }
$$

$\mathrm{D}=\max _{\mathrm{x}}\left\{\left|\mathrm{F}^{\prime}(\mathrm{x})-\mathrm{F}(\mathrm{x})\right|\right\}$

در رابطهُ بالا، xقادير مربوط به توزيع درجات در دو

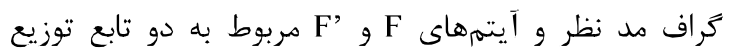
تجمعى درجه در زراف اصلى و نمونه اشاره دارند. جدول (9) نشان مى دهد كه الكوريتم نمونه نمونه
ييداست، روش קيشنهادى نسبت به الكُريتمهاى يايه، داراى

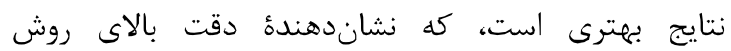
ييشنهادى در نمونه زيرى از زراف شبكهذهاى اجتماعى است.

(جدول -r): شبكههاى واقعى مورد آزمايش قرار گرفته به همراه

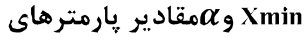

\begin{tabular}{|c|c|c|c|c|c|}
\hline رديف & نام شبكه & تعره & تعداد & مقدار & $\begin{array}{l}\text { مقدار } \\
X_{\text {min }}\end{array}$ \\
\hline 1 & Netscience & 1461 & 2742 & 3.41 & 4 \\
\hline r & $\begin{array}{c}\text { Internet_Routers- } \\
22 \text { july06 }\end{array}$ & 22963 & 48436 & 2.81 & 5 \\
\hline r & Karate & 34 & 78 & 2.12 & 2 \\
\hline i & IIep-th & 8360 & 113689 & 3.45 & 10 \\
\hline$\Delta$ & Football & 115 & 613 & 3.43 & 8 \\
\hline 8 & Dolphins & 62 & 159 & 3.47 & 6 \\
\hline v & Cond-mat & 16726 & 47594 & 3.48 & 16 \\
\hline$\wedge$ & Astro-ph & 16704 & 121251 & 3.45 & 45 \\
\hline 9 & Lesmis & 77 & 254 & 3.21 & 12 \\
\hline 1. & Celegansneural & 297 & 1017 & 3.36 & 11 \\
\hline 11 & Polbooks & 105 & 411 & 2.64 & 5 \\
\hline
\end{tabular}

(Table-2): Real-world networks with values of $\alpha$ and Xmin

(جدول - †): يارامترها و تنظيمات اوليه مورد نياز

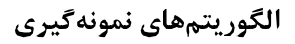

(Table-3): Parameter settings for testing of

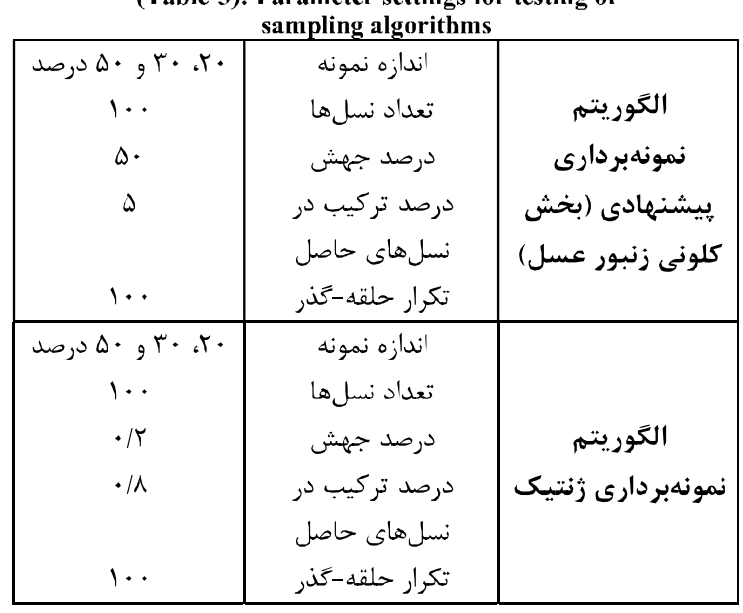

Xmin و

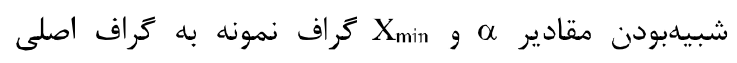
شبكه، نشاندهنده حفظ توزيع درجه قانون توانى در نمونه

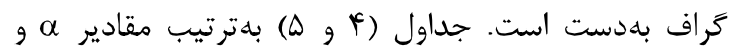
شبكه اصلى را قبل از نمونهبردارى و بعد از نمونهبردارى با روش ييشنهادى و الكوريتمهاى ديخر مقايسهشده نشان

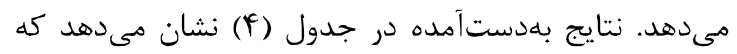

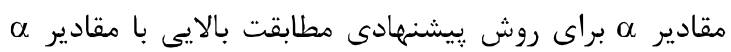


نمونه گيرى بيست درصد با روش ييشنهادى نسبت به ديخر روشهاى مقايسهشده در بيشتر شبكها نشان مى مدهد.

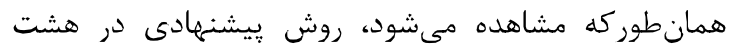

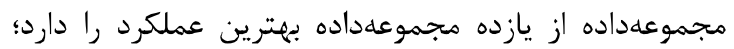

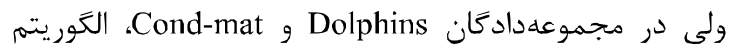
CSN بهتر بوده و در Netscience نيز الكوريتم NR عملكرد بهترى در حفظ ضريب خوشهبندى زراف دارد. جدول (9)

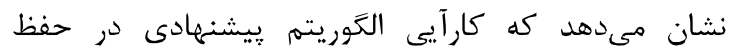

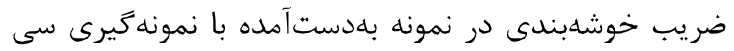
درصد نسبت به ديگر روشهاى مقايسهشده در هشت شبكه از يازده شبكه آزمايششده بالا است. در بين روشهاى ديكر ديكر دهاي

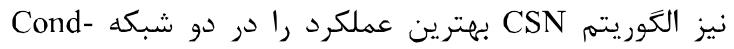

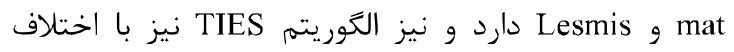

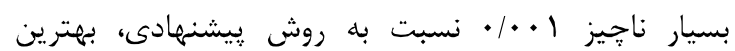
عملكرد را در مجموعهداده Celegansneural دارد.
استثناى مجموعهدادكان Internet_routers-22july06، در مابقى شبكها، مقادير كوجىترى (نزديك به صفر) را نسبت

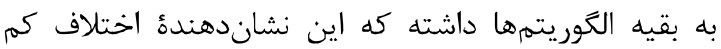
بين توزيع درجه گراف اصلى و نمونه گراف بهدستآمده از بله

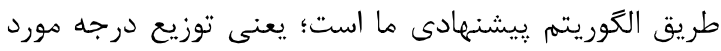

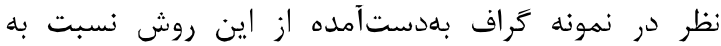
روشهاى مقايسهشده ديخر تا حد زيادى حفظ شده است.

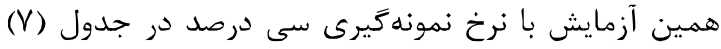

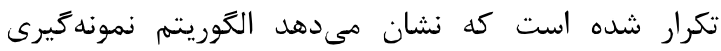

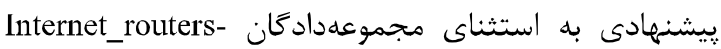
22july06 و Karate، مقادير كوجكترى را نسبت به بقيه الخوريتمها در مابقى شبكهما دارد.

r-F- آناليز بر اساس حفظ ضريب خوشهبندى

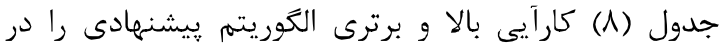

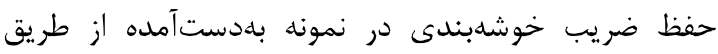

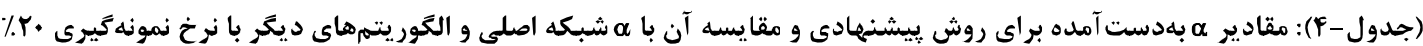

(Table-4): The obtained $\alpha$ values for the proposed method and compared it with $\alpha$ of main networks and compared algorithms at a

\begin{tabular}{|c|c|c|c|c|c|c|c|}
\hline & شبكه ممقادير & |روش پيشنههادى & الكوريته CSNN & الكوريته NRR & $\begin{array}{l}\text { نمونهبردارى } \\
\text { TIES } \\
\text { TIES }\end{array}$ & الكَور يتهم زُنتيك دارى با & تمونهبردارى روش \\
\hline Netscience & 3.41 & $\mathbf{3 . 3 4 3 8}$ & 2.3102 & 2.3179 & 2.7118 & 2.9118 & 1.6102 \\
\hline \begin{tabular}{|c|} 
Internet_Router \\
s-22_july6
\end{tabular} & 2.81 & 2.0777 & 2.482 & 2.0777 & 1.6777 & 2.0777 & 0.1518 \\
\hline \begin{tabular}{|l|} 
Karate \\
\end{tabular} & 2.12 & 2.1571 & 3.0082 & 3.275 & 3.0395 & 3.375 & 0.6272 \\
\hline Hep-th & 3.45 & 3.444 & 3.2599 & 3.5819 & 3.2819 & 3.4819 & 1.283 \\
\hline Football & 3.43 & 3.3913 & 3.0949 & 3.4913 & 3.0913 & 3.3137 & 1.349 \\
\hline Dolphins & 3.47 & 3.2727 & 4.1386 & 3.9222 & 3.6108 & 3.2222 & 4.1926 \\
\hline Cond-mat & 3.48 & 3.4698 & 3.159 & 3.0913 & 2.9274 & 3.4913 & 1.459 \\
\hline Astro-ph & 3.45 & 3.469 & 2.8918 & 3.2924 & 3.3924 & 3.4924 & 3.4924 \\
\hline Lesmis & 3.21 & 3.1429 & 2.3507 & 2.55 & 2.2459 & 2.651 & 0.5507 \\
\hline \begin{tabular}{|l|} 
Celegans-neural \\
\end{tabular} & 3.36 & 3.3904 & 2.6684 & 2.3738 & 2.1642 & 2.5738 & 0.2684 \\
\hline \begin{tabular}{|l|} 
Polbooks \\
\end{tabular} & 2.64 & 2.6011 & 3.1803 & 3.3161 & 1.7161 & 1.9161 & 3.255 \\
\hline
\end{tabular}

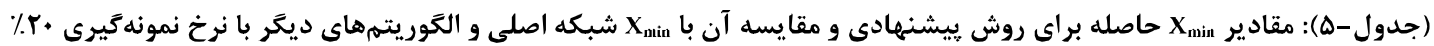
(Table-5): The obtained $X_{\min }$ values for the proposed method and compared it with $X_{\min }$ of main networks and compared algorithms at

\begin{tabular}{|c|c|c|c|c|c|c|c|}
\hline & شبكه اصلى & |روش ويشنههادى & الكوريته & الكوريته & $\begin{array}{l}\text { نمونهبردارى روش } \\
\text { TIES }\end{array}$ & التمونهبردارى با & تمونهبردارى روش \\
\hline Netscience & 4 & 4 & 3 & 3 & 3 & 4 & 2 \\
\hline $\begin{array}{c}\text { Internet_Route } \\
\text { rs-22july6 }\end{array}$ & 5 & 4 & 5 & 4 & 5 & 5 & 3 \\
\hline Karate & 2 & 2 & 1 & 2 & 1 & 3 & 5 \\
\hline Hep-th & 10 & 10 & 9 & 10 & 11 & 11 & 5 \\
\hline Football & 8 & 8 & 7 & 7 & 8 & 8 & 3 \\
\hline Dolphins & 6 & 6 & 5 & 6 & 7 & 5 & 4 \\
\hline Cond-mat & 16 & 15 & 13 & 13 & 18 & 14 & 24 \\
\hline
\end{tabular}




\begin{tabular}{|c|c|c|c|c|c|c|c|}
\hline Astro-ph & 45 & $\mathbf{4 4}$ & 42 & $\mathbf{4 3}$ & 42 & 41 & $\mathbf{1 2}$ \\
\hline Lesmis & 12 & $\mathbf{1 2}$ & 13 & 10 & $\mathbf{1 2}$ & 8 \\
\hline Celegansneural & 11 & $\mathbf{1 1}$ & 10 & $\mathbf{1 1}$ & 12 & 7 \\
\hline Polbooks & 5 & $\mathbf{5}$ & 6 & 8 & 6 & 4 \\
\hline
\end{tabular}

(جدول-\$): تحليل توزيع درجه بر حسب مقدار KS (با نرخ بيست درصد)

(Table-6): The analysis of degree distribution by KS value (with rate of $20 \%$ )

\begin{tabular}{|c|c|c|c|c|c|c|}
\hline نام شبكد & بيشنهادى الغوريتم & الكوريتهم CSSN & الكوريتم & TIES & الكوريتم رثنتيب دارى با & نمونهبردارى الكوريته \\
\hline Netscience & 0.34 & 0.35 & 0.36 & 0.45 & 0.39 & 0.37 \\
\hline $\begin{array}{c}\text { internet_routers- } \\
22 \mathrm{july} 06\end{array}$ & 0.29 & 0.28 & 0.31 & 0.33 & 0.36 & 0.57 \\
\hline Karate & 0.26 & 0.54 & 0.45 & 0.49 & 0.44 & 0.62 \\
\hline hep-th & 0.33 & 0.37 & 0.39 & 0.41 & 0.36 & 0.64 \\
\hline Football & 0.40 & 0.42 & 0.41 & 0.44 & 0.48 & 0.47 \\
\hline Dolphins & 0.23 & 0.28 & 0.27 & 0.39 & 0.34 & 0.53 \\
\hline cond-mat & 0.26 & 0.29 & 0.32 & 0.43 & 0.56 & 0.49 \\
\hline astro-ph & 0.30 & 0.30 & 0.31 & 0.47 & 0.32 & 0.37 \\
\hline Lesmis & 0.23 & 0.47 & 0.51 & 0.41 & 0.57 & 0.56 \\
\hline Celegansncural & 0.25 & 0.35 & 0.38 & 0.39 & 0.64 & 0.54 \\
\hline Polbooks & 0.44 & 0.49 & 0.42 & 0.39 & 0.58 & 0.43 \\
\hline
\end{tabular}

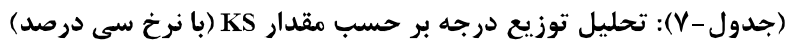

(Table-7): The analysis of degree distribution by KS value (with rate of $30 \%$ )

\begin{tabular}{|c|c|c|c|c|c|c|}
\hline نام شبكه & بيشنههادى الخوريتم & الكوريته CSN & اللكوريته & TIES روش & الخوريتم زنتيكى نارى با & نمونهبردارى الكوريتم \\
\hline Netscience & 0.27 & 0.35 & 0.35 & 0.32 & 0.32 & 0.37 \\
\hline $\begin{array}{c}\text { internet_routers- } \\
22 \text { july06 }\end{array}$ & 0.26 & 0.25 & 0.29 & 0.41 & 0.27 & 0.36 \\
\hline Karate & 0.25 & 0.54 & 0.44 & 0.37 & 0.15 & 0.18 \\
\hline hep-th & 0.33 & 0.35 & 0.38 & 0.57 & 0.58 & 0.47 \\
\hline Football & 0.26 & 0.34 & 0.30 & 0.38 & 0.26 & 0.36 \\
\hline Dolphins & 0.22 & 0.23 & 0.25 & 0.26 & 0.29 & 0.28 \\
\hline cond-mat & 0.29 & 0.29 & 0.33 & 0.51 & 0.37 & 0.46 \\
\hline astro-ph & 0.31 & 0.33 & 0.31 & 0.48 & 0.47 & 0.50 \\
\hline Lesmis & 0.20 & 0.41 & 0.37 & 0.32 & 0.38 & 0.48 \\
\hline Celegansneural & 0.25 & 0.35 & 0.38 & 0.44 & 0.52 & 0.58 \\
\hline Polbooks & 0.08 & 0.19 & 0.24 & 0.25 & 0.12 & 0.43 \\
\hline
\end{tabular}

(جدول -1) مقادير ضريب خوشهبندى بdدست آمده براى روش ييشنهادى و مقايسه آن با ميانغين ضريب خوشهبندى شبكه اصلى و

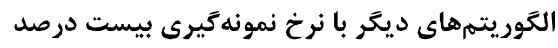

(Table-8): The obtained clustering coefficient values for the proposed method and compared it with clustering coefficient of main

\begin{tabular}{|c|c|c|c|c|c|c|c|}
\hline & خوشهبندى ضبك اصلى & روش ييشنهادى & الكَوريته & NRR الگوريتم & $\begin{array}{c}\text { نمونهبردارى } ر \text { روش } \\
\text { TIES }\end{array}$ & | الكوريتهم زنتيك & نمونهبر دارى روش \\
\hline Netscience & 0.637 & 0.532 & 0.467 & 0.549 & 0.352 & 0.489 & 0.321 \\
\hline \begin{tabular}{|c|} 
Internet_Router \\
s-22july6
\end{tabular} & 0.351 & 0.239 & 0.231 & 0.208 & 0.138 & 0.158 & 0.001 \\
\hline
\end{tabular}




\begin{tabular}{|c|c|c|c|c|c|c|c|c|}
\hline Karate & 0.571 & $\mathbf{0 . 3 5 1}$ & 0.334 & 0.299 & 0.229 & 0.229 & 0.22 \\
\hline Hep-th & 0.441 & $\mathbf{0 . 3 9 8}$ & 0.301 & 0.275 & 0.175 & 0.255 & 0.072 \\
\hline Football & 0.403 & $\mathbf{0 . 3 7 3}$ & 0.223 & 0.181 & 0.311 & 0.211 & 0.166 \\
\hline Dolphins & 0.259 & 0.216 & $\mathbf{0 . 2 2 9}$ & 0.113 & 0.103 & 0.127 & 0.207 \\
\hline Cond-mat & 0.620 & 0.489 & $\mathbf{0 . 5 5 3}$ & 0.375 & 0.285 & 0.435 & 0.353 \\
\hline Astro-ph & 0.638 & $\mathbf{0 . 5 4 1}$ & 0.467 & 0.521 & 0.431 & 0.391 & 0.499 \\
\hline Lesmis & 0.573 & $\mathbf{0 . 4 9 2}$ & 0.453 & 0.438 & 0.318 & 0.418 & 0.435 \\
\hline Celegansneural & 0.292 & $\mathbf{0 . 2 5 1}$ & 0.212 & 0.195 & 0.222 & 0.196 & 0.189 \\
\hline Polbooks & 0.487 & $\mathbf{0 . 3 6 9}$ & 0.307 & 0.327 & 0.277 & 0.247 & 0.149 \\
\hline
\end{tabular}

(جدول -9): ميانكين ضريب خوشهبندى بهدست آمده براى روش پييشنهادى و مقايسه آن با شبكه اصلى

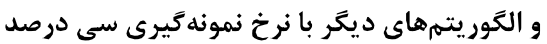

(Table-9): The obtained clustering coefficient values for the proposed method and compared it with clustering coefficient of main networks and compared algorithms at a sampling rate of $30 \%$

\begin{tabular}{|c|c|c|c|c|c|c|c|}
\hline & خوشهبندى شبك اصلى & روش رييشنهادى & الكوريتهم CSNN & الكوريته & $\begin{array}{l}\text { نمونهبردارى روش } \\
\text { TIES }\end{array}$ & |الكوريتم زنتنيك دارى با & نمونهبردارى روش \\
\hline Netscience & 0.637 & 0.562 & 0.497 & 0.551 & 0.386 & 0.509 & 0.351 \\
\hline \begin{tabular}{|c|} 
Internet_Router \\
s-22july6
\end{tabular} & 0.351 & 0.289 & 0.261 & 0.248 & 0.178 & 0.218 & 0.141 \\
\hline Karate & 0.571 & 0.481 & 0.473 & 0.229 & 0.259 & 0.269 & 0.28 \\
\hline Hep-th & 0.441 & 0.378 & 0.371 & 0.315 & 0.235 & 0.275 & 0.122 \\
\hline Football & 0.403 & 0.383 & 0.253 & 0.231 & 0.351 & 0.261 & 0.216 \\
\hline Dolphins & 0.259 & 0.213 & 0.189 & 0.127 & 0.162 & 0.167 & 0.227 \\
\hline Cond-mat & 0.620 & 0.549 & 0.583 & 0.435 & 0.345 & 0.375 & 0.393 \\
\hline Astro-ph & 0.638 & 0.571 & 0.497 & 0.551 & 0.471 & 0.411 & 0.529 \\
\hline Lesmis & 0.573 & 0.492 & 0.523 & 0.478 & 0.368 & 0.468 & 0.465 \\
\hline Celegansneural & 0.292 & 0.281 & 0.202 & 0.185 & 0.282 & 0.19 & 0.239 \\
\hline Polbooks & 0.487 & 0.399 & 0.337 & 0.357 & 0.197 & 0.277 & 0.209 \\
\hline
\end{tabular}

(جدول -•(): ميانغين ضريب خوشهبندى بهدست آمده براى روش ويشنهادى و مقايسه آن با شبكه اصلى

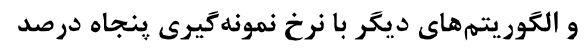

(Table-10): The obtained clustering coefficient values for the proposed method and compared it with clustering coefficient of main networks and compared algorithms at a sampling rate of $50 \%$

\begin{tabular}{|c|c|c|c|c|c|c|c|}
\hline & خوشهبندى ضبك اصلى & روش پيششنهادى & الكوريتهم CSSN & الكَوريته & $\begin{array}{l}\text { نمونهبردارى } \\
\text { TIES }\end{array}$ & |العور يتم زنتيكى دارى با & نمونهبر دارى روش \\
\hline Netscience & 0.637 & 0.623 & 0.547 & 0.57 & 0.43 & 0.569 & 0.401 \\
\hline \begin{tabular}{|c|}
$\begin{array}{c}\text { Internet_Router } \\
\text { s-22july6 }\end{array}$ \\
\end{tabular} & 0.351 & 0.329 & 0.321 & 0.308 & 0.238 & 0.258 & 0.101 \\
\hline Karate & 0.571 & 0.531 & 0.530 & 0.289 & 0.319 & 0.329 & 0.31 \\
\hline Hep-th & 0.441 & 0.428 & 0.401 & 0.375 & 0.265 & 0.335 & 0.172 \\
\hline Football & 0.403 & 0.413 & 0.303 & 0.261 & 0.391 & 0.311 & 0.256 \\
\hline Dolphins & 0.259 & 0.263 & 0.229 & 0.267 & 0.247 & 0.217 & 0.287 \\
\hline Cond-mat & 0.620 & 0.589 & 0.633 & 0.475 & 0.375 & 0.415 & 0.433 \\
\hline Astro-ph & 0.638 & 0.621 & 0.557 & 0.611 & 0.521 & 0.471 & 0.579 \\
\hline Lesmis & 0.573 & 0.522 & 0.545 & 0.527 & 0.406 & 0.508 & 0.525 \\
\hline Celegansneural & 0.292 & 0.321 & 0.262 & 0.235 & 0.317 & 0.248 & 0.269 \\
\hline Polbooks & 0.487 & 0.459 & 0.387 & 0.417 & 0.257 & 0.327 & 0.239 \\
\hline
\end{tabular}


بقيه روشها در همه مجموعهدادهها بهاستثناى Lesmis

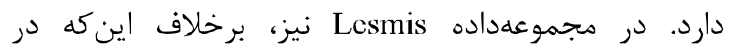
نمونه

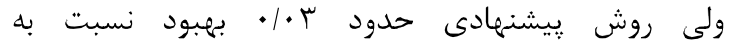
نمونه كيرى سى درصد دارد؛ درحالى كه در روش CSN،

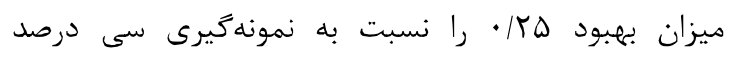

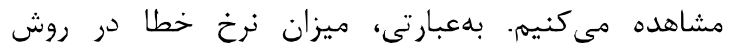

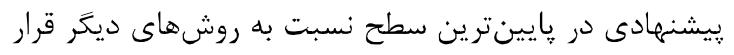

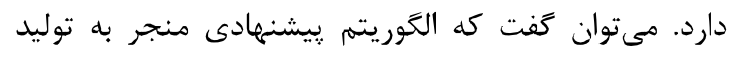
نمونهشبكه با كيفيت نزديك به كيفيت شبكه اصلى شده، كه

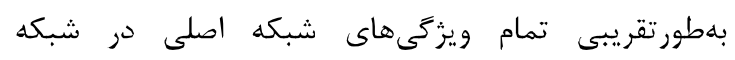
نمونه كيرى حفظ شده است.
نتايج حاصل از جدول (·) نيز نشان مىدهد كه كارآيى الكوريتهم ييشنهادى در حفظ ضريب خوشهبندى در نمونه بهدستآمده با نمونه

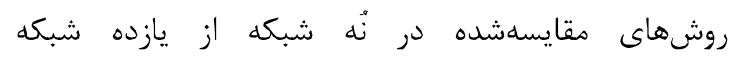

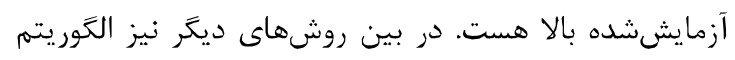

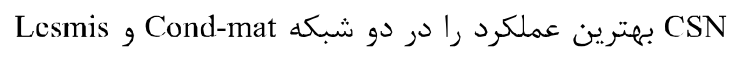
دارد. تحليل نتايج بهدستآمده از هر سه جدول (ی)، 9 و • (1)

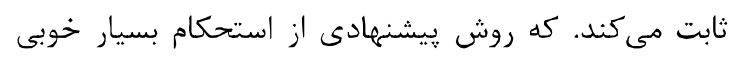

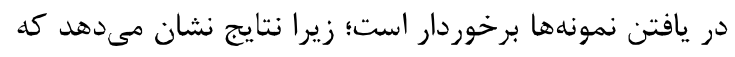

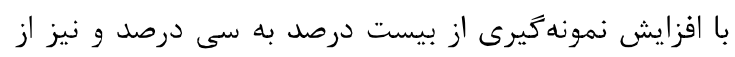

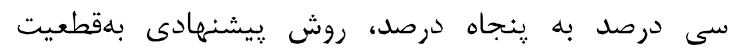

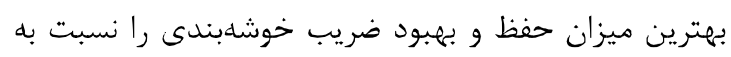

(جدول -1()): تعداد جوامع بهدست آمده با الكوريتم LP-LPA در نمونههاى حاصله با روش هيشنهادى

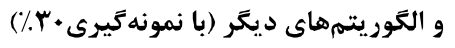

(Table-11): The number of discovered communities using LP-LPA for obtained sampling by the proposed method and the other

\begin{tabular}{|c|c|c|c|c|c|c|c|}
\hline & تعداد جوامع & روش ِيششنهادى & الكوريتم & الخوريتم NR & $\begin{array}{l}\text { نمونهبردارى روش } \\
\text { TIES }\end{array}$ & الكَوريتهم رُنتيك بمونى بارى & نمونهبردارى روش \\
\hline Karate & 2 & 2 & 2 & 3 & 3 & $3 \pm 1$ & $4 \pm 1$ \\
\hline Dolphins & 2 & 3 & 5 & 4 & 4 & $5 \pm 2$ & $7 \pm 2$ \\
\hline Football & 12 & 9 & 10 & 7 & 6 & $13 \pm 7$ & $15 \pm 5$ \\
\hline Polbook & 3 & 4 & 5 & 6 & 4 & $5+1$ & $5+2$ \\
\hline Lesmis & 2 & 2 & 4 & 4 & 7 & $8 \pm 4$ & $12 \pm 3$ \\
\hline
\end{tabular}

ويزَّى ساختار انجمنى دارد؛ ولى در Football، روش

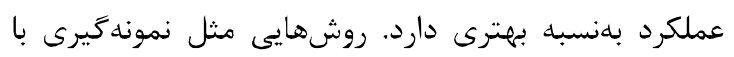

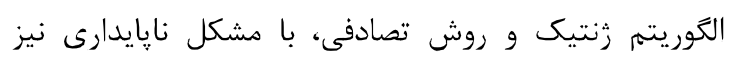

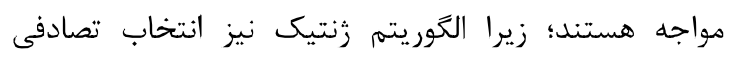

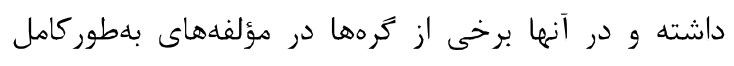

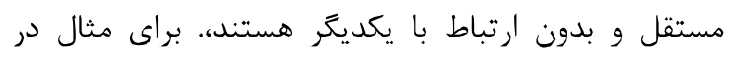
مجموعهداده Lesmis كه در شكل (1) نشان داده شده است، مىتوانيد نتايج روش نايايدارى مثل نمونهبردارى مبتنى بر

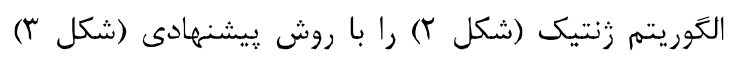
مقايسه كنيد. واضح است كه روش ييشنههادى توانسته است بلهرستى هر دو جامعه را در نمونه حاصل، حفظ كند؛ ولى روشى مثل الكوريتم زنتيك هنين ويزگى بارزى را ندارد و

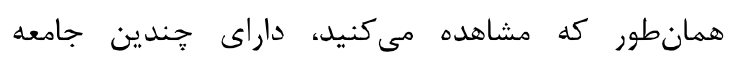

$$
\text { تك گرهى است. }
$$

كَفتنى است كه نمونهبردارى شبكه هاى واقعى بهدليل

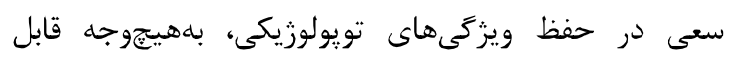
استفاده براى شبكههاى تصادفى نيست. توجه داشته باشيم

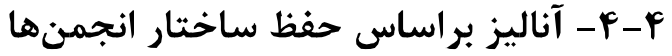

Sarate, در اين قسمت با استفاده از فقط جهار شبكه واقعى

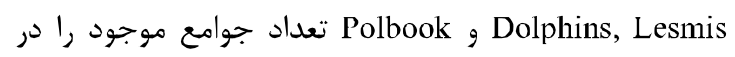
نمونههاى بdدستآمده در نمونهيرى باهم مقايسه كرديم زيرا در مابقى مجموعهدادگان، تعداد جوامع نامشخص هست.

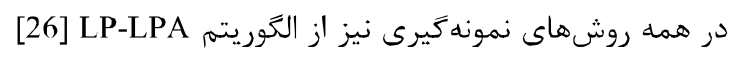
براى يافتن جوامع در شرايط بلهور كامل يكسان استفاده

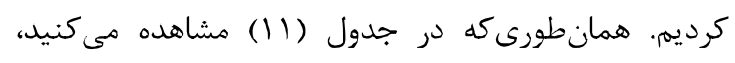

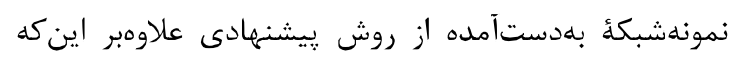
ويزگى هاى تويولوزيكى و مدل شبكه اصلى يعنى مقياسِ آزاد' بودن را حفظ كرده، بلكه ويثزى حفظ ساختار انجمنى و توزيع قانون توانى را نيز بهطوركامل دارد؛ لذا كارايى

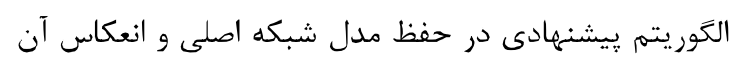
در نمونه بلهدستآمده نسبت به روشهاى ديخر بهطور كامل

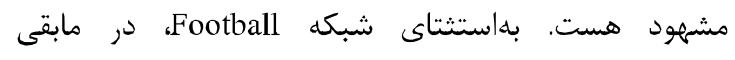

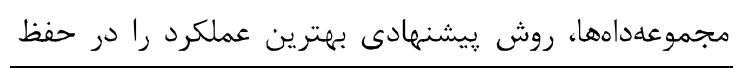
${ }^{1}$ Scale Free 

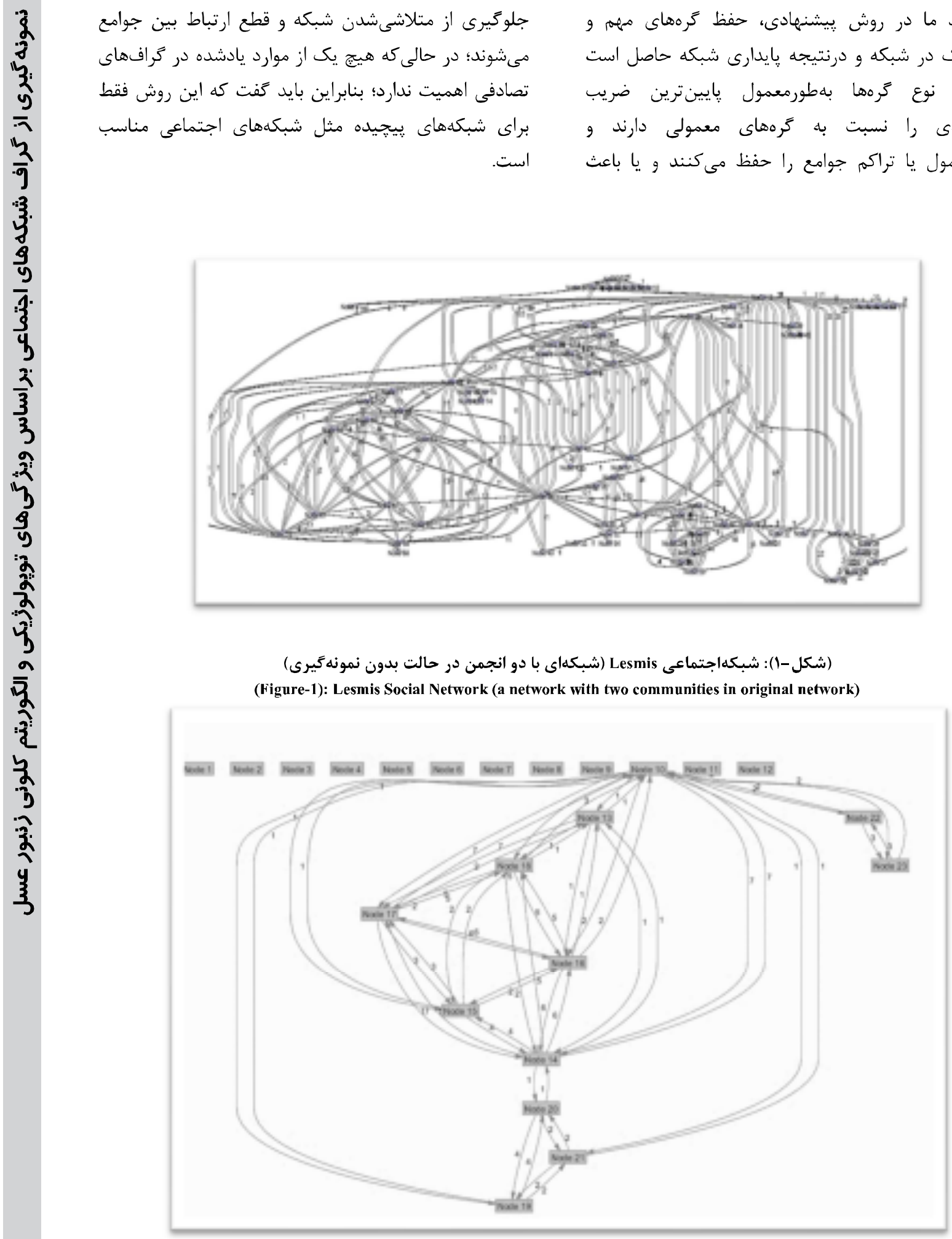

(شكل - Y): نمونه شبكه Lesmis بهدست آمده با استفاده از روش نمونه ميرى زنتيك

(Figure-2): The obtained sample from Lesmis Social Network using genetic-based sampling algorithm

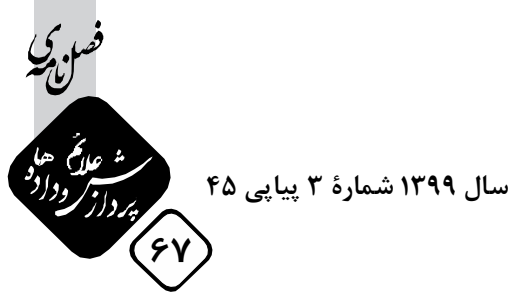




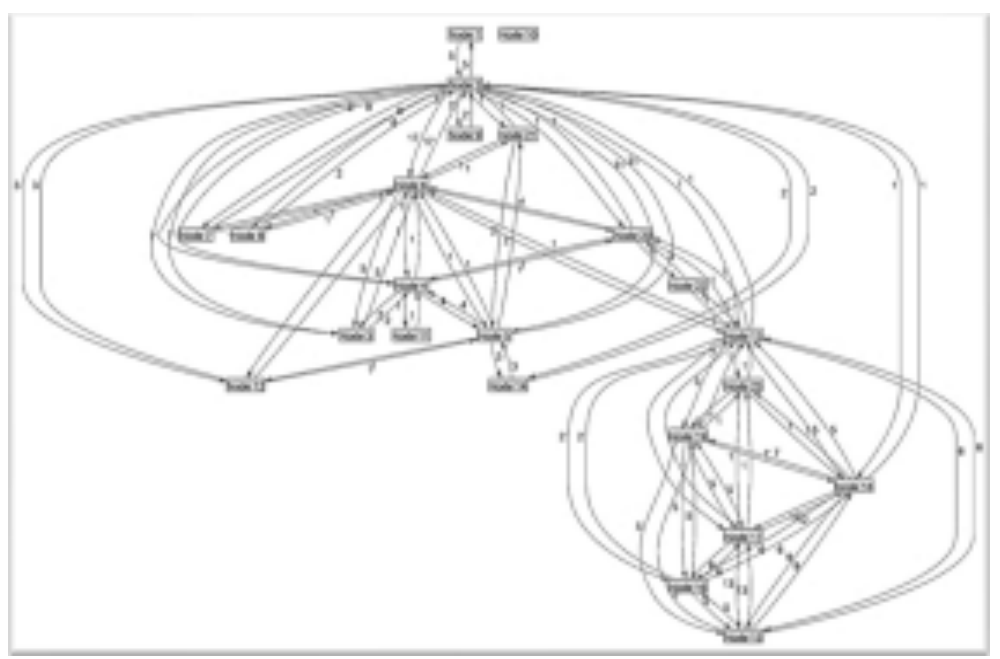

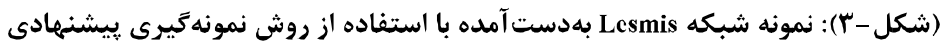

(Figure-3): The obtained sample from Lesmis Social Network using proposed sampling algorithm

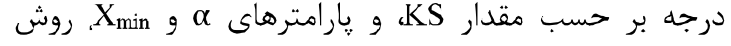

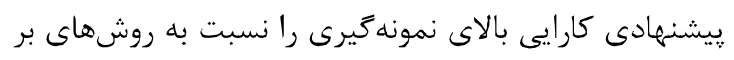

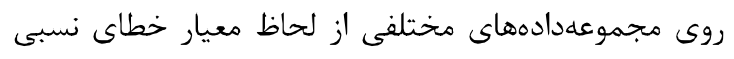

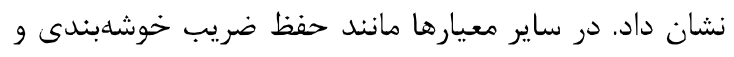

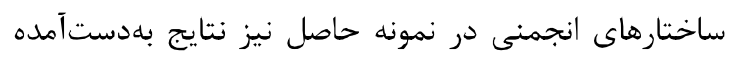

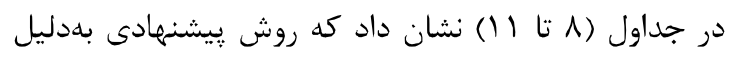

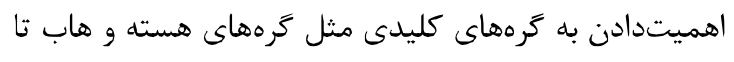

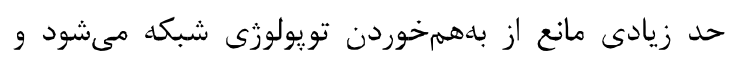

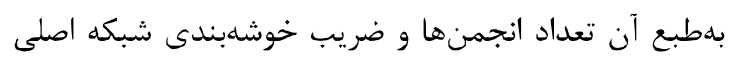

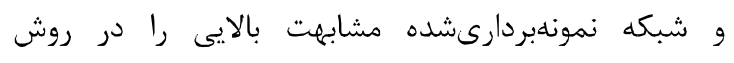
پيشنهادى نشان مى دهد.

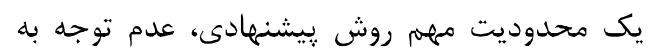

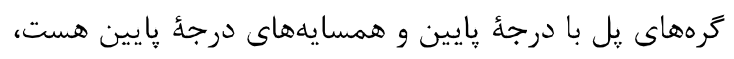

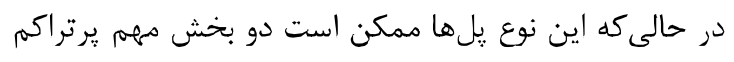

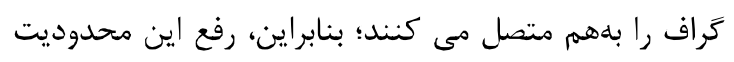

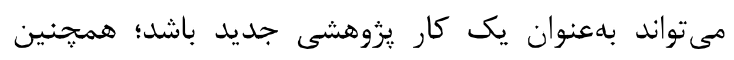

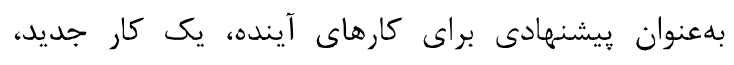

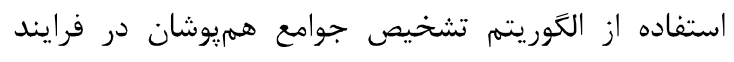

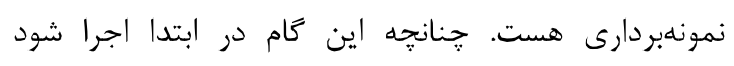

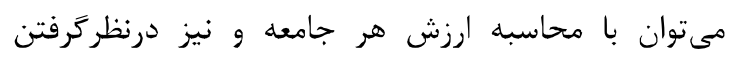

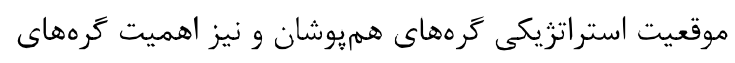

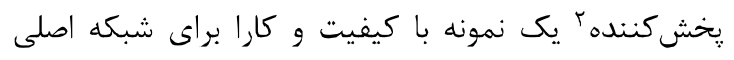

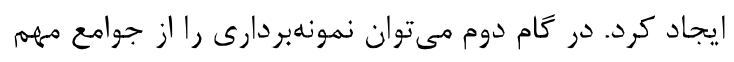

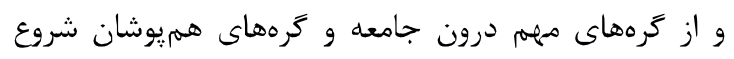
كرد و تا جوامع ضعيف ادامه دادم درن

${ }^{2}$ Spreader

\section{ه - نتيجه}

در اين مقاله براى رفع مشكلات الكوريتمهاى نمونه مانيرى

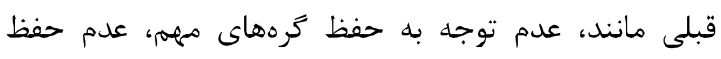

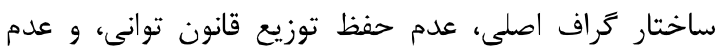

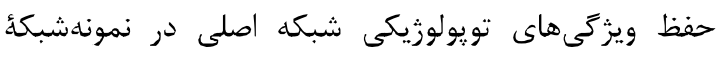

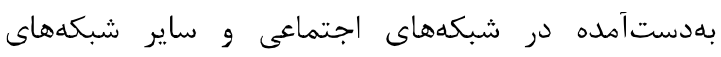

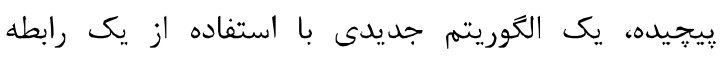

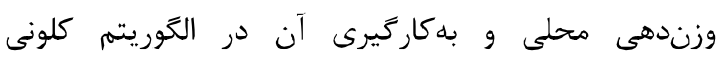

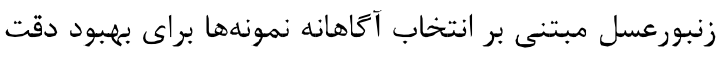

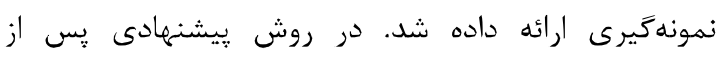

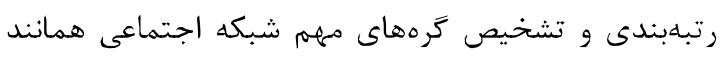

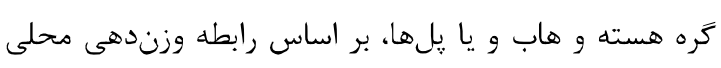

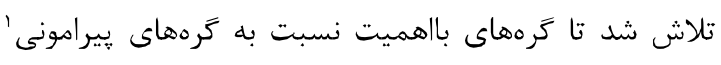

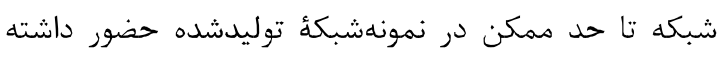

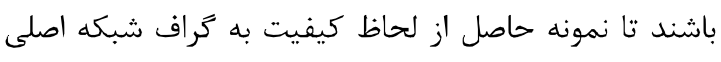

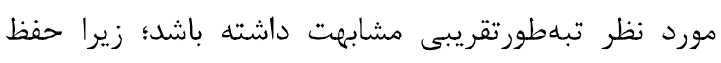

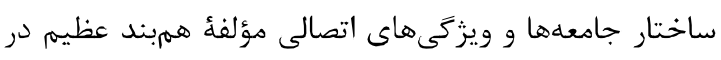

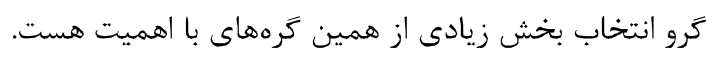

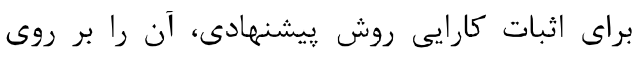

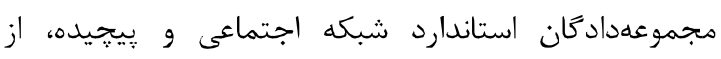

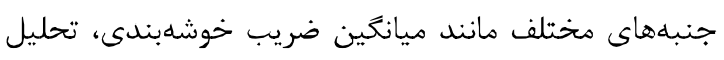

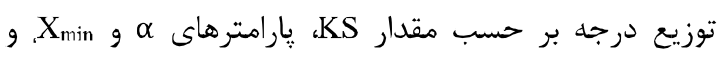

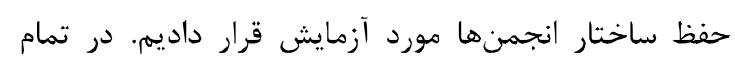

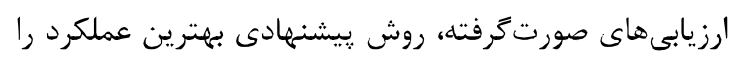

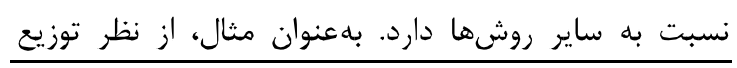
${ }^{1}$ periphery 
Decision support systems, vol. 51, no. 3, pp. 506-518, 2011.

[13] P. Krömer and J. Platoš, "Genetic algorithm for sampling from scale-free data and networks," in Proceedings of the 2014 annual conference on genetic and evolutionary computation, 2014, pp. 793-800: ACM

[14] N. Metropolis, A. W. Rosenbluth, M. N. Rosenbluth, A. H. Teller, and E. Teller, "Equation of state calculations by fast computing machines," The journal of chemical physics, vol. 21, no. 6, pp. 1087-1092, 1953.

[15] L. A. Goodman, "Snowball sampling," The annals of mathematical statistics, pp. 148-170, 1961.

[16] L. Lovász, "Random walks on graphs: A survey," Combinatorics, Paul erdos is eighty, vol. 2, no. 1, pp. 1-46, 1993.

[17] D. D. Heckathorn, "Respondent-driven sampling: a new approach to the study of hidden populations," Social problems, vol. 44, no. 2, pp. 174-199, 1997.

[18] S. Ye, J. Lang, and F. Wu, "Crawling online social graphs," in 2010 12th International AsiaPacific Web Conference:IEEEP, pp. 236-242, 2010.

[19] A. Rezvanian and M. R. Meybodi, "Sampling social networks using shortest paths," Physica A: Statistical Mechanics and its Applications, vol. 424, pp. 254-268, 2015.

[20] A. Sevilla, A. Mozo, and A. F. Anta, "Node sampling using random centrifugal walks," Journal of Computational Science, vol. 11, pp. 34-45, 2015.

[21] C. Tong, Y. Lian, J. Niu, Z. Xie, and Y. Zhang, "A novel green algorithm for sampling complex networks," Journal of Network and Computer Applications, vol. 59, pp. 55-62, 2016.

[22] N. Ahmed, J. Neville, and R. R. Kompella, "Network sampling via edge-based node sclection with graph induction," 2011.

[23] K. Brádler, P.-L. Dallaire-Demers, P. Rebentrost, D. Su, and C. Weedbrook, "Gaussian boson sampling for perfect matchings of arbitrary graphs," Physical Review A, vol. 98, no. 3, pp. 032310, 09/10/2018.

[24] J. Zhao, P. Wang, J. C. S. Lui, D. Towsley, and X. Guan, "Sampling online social networks by random walk with indirect jumps," Data Mining and Knowledge Discovery, journal article vol. 33, no. 1, pp. 24-57, January 01. 2019.

[25] Y. Xie, S. Chang, Z. Zhang, M. Zhang, and L. Yang, "Efficient sampling of complex network with modified random walk strategies," Physica

\section{6- References}

[1] E. Katz, P. F. Lazarsfeld, and E. Roper, Personal influence: The part played by people in the flow of mass communications. Routledge, 2017.

[2] N. B. Ellison, J. Vitak, R. Gray, and C. Lampe, "Cultivating social resources on social network sites: Facebook relationship maintenance behaviors and their role in social capital processes," Journal of Computer-Mediated Communication, vol. 19, no. 4, pp. 855-870, 2014.

[3] M. Irani and M. Haghighi, "The Impact of Social Networks on the Internet Business Sustainability (With Emphasis on the Intermediary Role of Entrepreneurial Purpose of Online Branches of Mellat Bank's Portal)," Journal of Information Technology Management, vol. 5, no. 4, pp. 23-46, 2013.

[4] M. Emirbayer and J. Goodwin, "Network analysis, culture, and the problem of agency," American journal of sociology, vol. 99, no. 6, pp. 1411-1454, 1994.

[5] J. Tang, J. Sun, C. Wang, and Z. Yang, "Social influence analysis in large-scale networks," in Proceedings of the 15th ACM SIGKDD international conference on Knowledge discovery and data mining, 2009, pp. 807-816: ACM .

[6] J. Török, Y. Murase, H.-H. Jo, J. Kertész, and K. Kaski, "What big data tells: sampling the social network by communication channels," Physical Review E, vol. 94, no. 5, pp. 052319, 2016.

[7] M. Papagelis, G. Das, and N. Koudas, "Sampling online social networks," IEEE Transactions on knowledge and data engineering, vol. 25, no. 3, pp. 662-676, 2013.

[8] K. Dempsey, K. Duraisamy, H. Ali, and S. Bhowmick, "A parallel graph sampling algorithm for analyzing gene correlation networks," Procedia Computer Science, vol. 4, pp. 136-145, 2011.

[9] J. Leskovec and C. Faloutsos, "Sampling from large graphs," in Proceedings of the 12th ACM SIGKDD international conference on Knowledge discovery and data mining, 2006, pp. 631-636: ACM.

[10] S. Yoon, S. Lee, S.-H. Yook, and Y. Kim, "Statistical properties of sampled networks by random walks," Physical Review E, vol. 75, no. 4, pp. 046114, 2007.

[11] S.-H. Yoon, K.-N. Kim, J. Hong, S.-W. Kim, and S. Park, "A community-based sampling method using DPL for online social networks," Information Sciences, vol. 306, pp. 53-69, 2015.

[12] E. M. Airoldi, X. Bai, and K. M. Carley, "Network sampling and classification: An investigation of network model representations," 
A: Statistical Mechanics and its Applications, vol. 492, pp. 57-64, 2018.

[26] K. Berahmand and A. Bouyer, "LP-LPA: A link influence-based label propagation algorithm for discovering community structures in networks," International Journal of Modern Physics B, vol. 32, no. 06, pp. 1850062, 2018.

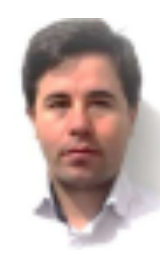

$$
\begin{aligned}
& \text { عسكَرعلى بوير دانشيار كروه مهندسى }
\end{aligned}
$$

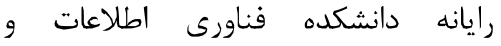

$$
\begin{aligned}
& \text { مهندسى رايانه در دانشگاه شهيد مدنى } \\
& \text { آذربايجان بوده كه در سال • وبا، مقطع } \\
& \text { دكترا را در رشته مهندسى رائ رايانه از }
\end{aligned}
$$

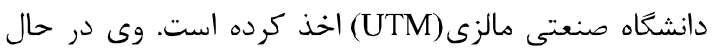

حاضر مدير مسئول آزمايشگًاه يروهشى رايانش توزيعى و

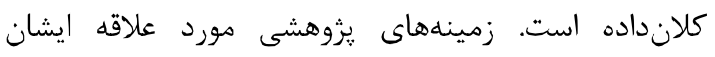

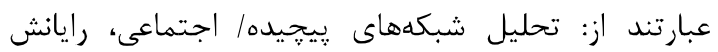

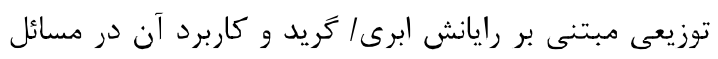

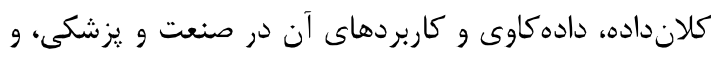
امنيت شبكههاى رايانهاى و محيطهاى توزيعى.

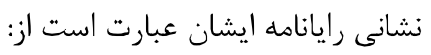
a.bouyer@azaruniv.ac.ir

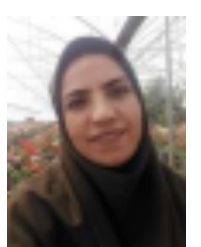

سميه نوروزى تحيلات كارشناسى

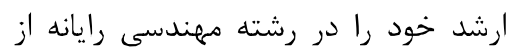

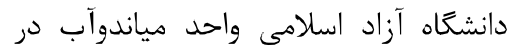
سال هوبا اخذ كرده است. زمينههاى يزوهشى مورد علاقه ايشان عبارتند از:

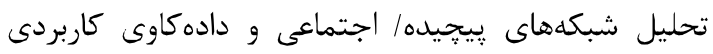
است.

$$
\text { نشانى رايانامه ايشان عبارت است از: }
$$

someiyenorozi2014@gmail.com

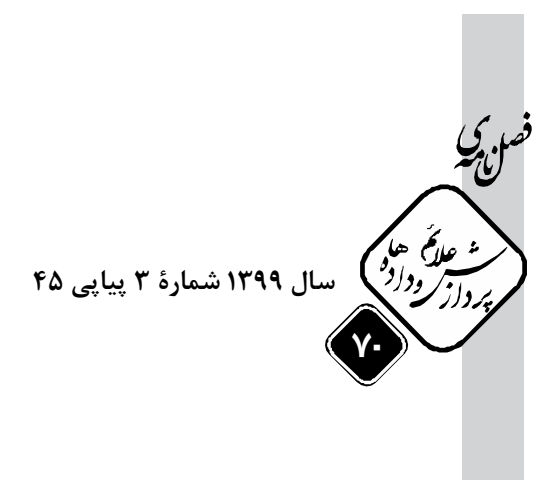

